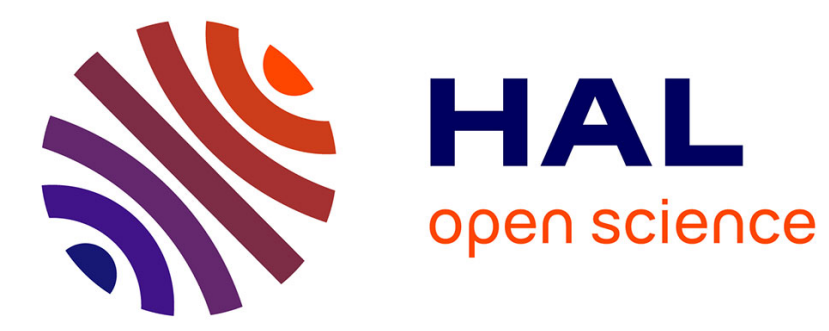

\title{
Target capital ratio and optimal channel(s) of adjustment: A simple model with empirical applications to European banks \\ Yann Braouezec, Keyvan Kiani
}

\section{To cite this version:}

Yann Braouezec, Keyvan Kiani. Target capital ratio and optimal channel(s) of adjustment: A simple model with empirical applications to European banks. Applied Economics, 2021, 53 (13), pp.14351462. halshs-03341768

\section{HAL Id: halshs-03341768 \\ https://shs.hal.science/halshs-03341768}

Submitted on 12 Sep 2021

HAL is a multi-disciplinary open access archive for the deposit and dissemination of scientific research documents, whether they are published or not. The documents may come from teaching and research institutions in France or abroad, or from public or private research centers.
L'archive ouverte pluridisciplinaire HAL, est destinée au dépôt et à la diffusion de documents scientifiques de niveau recherche, publiés ou non, émanant des établissements d'enseignement et de recherche français ou étrangers, des laboratoires publics ou privés. 


\title{
Target capital ratio and optimal channel(s) of adjustment: A simple model with empirical applications to European banks
}

\author{
Yann BRAOUEZEC ${ }^{*} \quad$ Keyvan KIANI ${ }^{\dagger}$
}

August 24, 2020

\begin{abstract}
Why do banks decide to reach their target capital ratio by selling assets and/or issuing new shares? To answer this question, we offer a simple framework in which each channel of adjustment is costly; underwriting and dilution costs for equity issuance, profit reduction and price impact for asset sale. We make the assumption that the aim of the bank is to minimize the total adjustment cost subject to the target's constraint and we derive its optimal strategy. The solution is formulated in terms of two critical thresholds for which we give an explicit formula. We then compare our model's predictions to the decisions taken by two European systemic banks (Deutsche Bank and UniCredit) to issue new shares in 2017 and for which the target ratio was publicly disclosed. We show that the predictions of the model are consistent with the observed decisions.
\end{abstract}

Keywords: Equity issuance, asset sale, price impact, target capital ratio, systemic banks.

*IESEG School of Management, CNRS-LEM, UMR 9221, Paris campus, Socle de la Grande Arche, 1 Parvis de la Défense, 92044 Paris La Défense Cedex, y.braouezec@ieseg.fr.

${ }^{\dagger}$ IESEG School of Management, CNRS-LEM, UMR 9221, Paris campus, Socle de la Grande Arche, 1 Parvis de la Défense, 92044 Paris La Défense Cedex, k.kiani@ieseg.fr. 


\section{Introduction}

In the aftermath of the global financial crisis of 2008, as a response to the deficiencies of the current banking regulation (Basel I or Basel II), regulators designed a new framework called Basel III (first published in 2010 and updated in 2011), intended to provide a foundation for a resilient banking system that will help avoid the build-up of systemic vulnerabilities. Under Basel III, regulators place a greater focus on going-concern loss-absorbing capital called Tier 1 capital, the best form of capital. Compared to Basel II, the minimum Tier 1 risk-based capital requirement defined as Tier 1 divided by the risk-weighted assets ( $\frac{\text { Tier } 1}{\mathrm{RWA}}$ ) is now higher and bank dependent due to the existence of buffers that depend upon the characteristics of each bank. A new Tier 1 risk-unweighted capital requirement, called the leverage ratio and defined as Tier 1 divided by the (total) exposure $\left(\frac{\text { Tier } 1}{\text { Exposure }}\right)$ has also been introduced ${ }^{1}$ and will be enforced in 2023. After this date, banks will thus have to comply with two Tier 1 capital ratios. In the empirical literature on the subject, it is shown that large banks maintain their risk-based capital ratios higher than the minimum required (e.g., [Berger et al., 2008, Memmel and Raupach, 2010]), which suggests the existence of a target capital ratio. Interestingly, some banks even disclose their target ratio. For instance, Deutsche Bank and Unicredit announced in March, 2017 a target Common Equity Tier 1 risk-based capital ratio equal to $14.1 \%$ and $12.9 \%$ respectively. To reach this target capital ratio, a given bank must thus adjust its balance sheet and there are two main (non-exclusive) channels of adjustments ([Gropp et al., 2019], [Cohen and Scatigna, 2016], [Juelsrud and Wold, 2020]). A bank can increase its regulatory capital ratio by increasing the numerator of the capital ratio (capital increase) or by decreasing the denominator of the capital ratio (asset shrinking/risk-reduction).

As all large corporations, a large bank can increase its capital ratio by issuing new equity, that is, by selling new shares through a capital increase. A bank can also sell a portion of its risky assets to repay its debt and this increases its capital ratio. As opposed to most corporations, a bank may also increase its capital ratio by using a risk-reduction strategy, that is, it can sell a portion of its risky assets in order to decrease its risk-weighted assets (RWA), the denominator of the capital ratio. Each channel of adjustment (capital increase, asset shrinking/riskreduction) turns out to be costly. Consider the capital increase channel. Issuing new stocks via an underwritten rights offering is far from being free as there are direct costs (underwriter compensation, registration and listing fees...) and indirect costs (stock price reaction to the offering announcement, see [Eckbo et al., 2007] for a comprehensive review and discussion). Moreover, this new issuance will also dilute existing shareholders since in percentage, their ownership will decrease. Consider now the asset shrinking/risk-reduction channel. Selling a large amount of risky assets may negatively impact the price of these assets due to the existence of a price impact (e.g., [French et al., 2010, Shleifer and Vishny, 2011, Greenwood et al., 2015]), and this may in turn decrease the capital of the bank. Moreover, when a bank sells a portion of its risky assets (and/or replace high risk weights assets with low risk weights assets), the expected profitability of that bank

\footnotetext{
${ }^{1}$ This ratio is designed to act as a backstop against risk-weighted assets that would be considered as too low by regulators.
} 
will also decrease.

It is the aim of the present paper to offer a theoretical model in which a large bank seeks to reach (in the short term) its target capital ratio by considering the two main channels of adjustment discussed above when each channel is costly. We make the natural assumption that the bank chooses the channel of adjustment (possibly a mix) that minimizes the overall cost of adjustment. The choice of the channel(s) of adjustment thus is formulated as an optimization problem which is in general non-linear. Depending upon the parameters, it may be more cost-efficient for the bank either to issue new shares or to sell the risky assets or even to do both, and we derive the optimal strategy of the bank. To facilitate the confrontation with observed decisions, we formulate the optimal strategy in terms of two critical thresholds (indeed critical spread) $c_{l}$ and $c_{h}$ (with $c_{l}<c_{h}$ ) where a critical spread is defined as the total issuance cost divided by the gross proceeds. We show that when the observed spread is lower than the lowest critical spread $c_{l}$, it is optimal for the bank to issue new shares only. On the other hand, when the observed spread is higher than the highest critical spread denoted $c_{h}$, it is optimal to sell risky assets only. In between, it is optimal to both issue new stocks and sell a portion of the risky assets.

The first contribution of this paper is theoretical in that we provide a complete and explicit solution to the optimization problem, that is, a closed form solution for the two critical thresholds $c_{l}$ and $c_{h}$ that are also of interest for regulators and supervisors. From a financial stability point of view, the greater these two thresholds are, the better it is. Everything else equal, when $c_{l}$ is high, this increases the chance that the bank will issue new stocks only. To the best of our knowledge, it is the first paper that attempts to incorporate the possibility for the bank to issue new stocks when each channel of adjustment (asset sale, equity issuance) is costly. In most models, only deleveraging is considered (e.g., [Braouezec and Wagalath, 2018], [Duarte and Eisenbach, 2015], [Greenwood et al., 2015]).

The second contribution of this paper is empirical in that we exploit the recent capital increase of two European large banks to test the predictions of the model. In the first quarter of 2017, two European Global Systemically Important banks (G-SIBs), Deutsche Bank and UniCredit decided to issue new shares via an underwritten rights offering. Interestingly, they publicly disclosed their target capital ratio, expressed in terms of the CET1 capital ratio. Equipped with this information, the (model) parameters can be calibrated and we are now in a position to test whether or not our model is able to predict the optimal behavior of each bank. In both cases, the observed decisions are consistent with our theoretical predictions. The observed cost is lower than the lowest critical spread so that it is optimal for the bank to issue new shares only, which is exactly what they did. It may be worthwhile to mention that in June, 2016, the Eurosystem started to make purchases under its new corporate sector purchase programme (CSPP) in order to support the EU banking sector assets.

To complement the empirical analysis of these two banks, we also consider the smallest (nonsystemic) banks listed on the website of the European Banking Authority (EBA) for which the exposure measure is between $€ 200$ billion and $€ 250$ billion. Assuming, as in [Altınkılıç and Hansen, 2000], 
that the spread paid is a U-shaped function of the gross proceeds, we show that our bank-by-bank result might explain the empirical finding of [De Jonghe and Öztekin, 2015], namely that it is optimal for small banks to sell their risky assets rather than to issue new shares.

This paper is related to the literature on bank's target capital ratio and/or bank's channels of adjustments, see for instance [Bakkar et al., 2019], [Berger et al., 2008],[Kok and Schepens, 2013], [Memmel and Raupach, 2010], [Öztekin and Flannery, 2012], [Shimizu, 2015] but departs from it in two respects. First, as opposed to this literature, we consider a theoretical model that we calibrate for each bank using public data and we compare the observed decision with its predictions, i.e., we do not test any statistical model. Second, we do not consider a partial adjustment model in which it may take several years for the bank, everything else equal, to reach the target capital ratio because the speed of adjustment is lower than one. Within our framework, we consider a two-period model, say date 0 and date 1 , and we assume that the target should be reached at time 1 , that is, we make the implicit assumption that the speed of adjustment is equal to one. Since we consider a short period (few months), we exclude the possibility to increase retained earnings to reach the target.

The rest of this paper is organized as follows. In the second section, we present a literature review on the subject. In the third section, we present our theoretical framework and then state our theoretical results. In the fourth section, we present in detail the way we calibrate the parameters of the model and discuss the capital increase done by two European systemic banks in the first quarter of 2017. In the fifth section, we briefly consider the case where the spread is a $U$-shaped function of the gross proceeds. The last section of the paper is devoted to a brief conclusion.

\section{Literature review: banks capital requirements and channels of adjustment}

Capital structure: debt versus equity. The literature on capital structure began with the so-called Modigliani-Miller theorem which states that the value of a firm is invariant with respect to its capital structure, that is, whether the firm is financed with equity only, debt only or a mix (i.e., debt and equity) has no impact on its value. In the Modigliani-Miller world, the capital structure only impacts the distribution of the surplus generated by the economic activity of the firmthe earning before interest and taxes (EBIT)-distributable to claim-holders (debt holders/equity holders). Consider the situation at a given point in time and let $C$ be the financial expenses such as the coupon of a bond to be paid to bondholders at that time. When there is no default risk and no corporate income tax, bondholders receive $C$ (for sure) while shareholders receive EBIT $-C$. The sum of the revenues (perceived by bondholders and shareholders) is equal to EBIT and this means that the capital structure, that is, whether the firm is financed with equity only or with a mix, has no impact on the value of the firm (here the EBIT) but only impacts its distribution ${ }^{2}$. This famous

\footnotetext{
${ }^{2}$ See [Braouezec, 2010] for a classical and modern presentation of this result. The modern approach makes use of continuous-time models together with the no-arbitrage principle.
} 
invariance result published in 1958 makes however a number of important assumptions-complete information, homemade leverage, risk class, no bankruptcy, no corporate income tax-that are not always realistic. We refer to [Stiglitz, 1988] for a lucid discussion of these assumptions. Since the publication of the Modigliani and Miller article, the aim of the literature on the subject has been precisely to relax these assumptions in order to inquire (theoretically and empirically) whether or not the capital structure of firms matters. This literature is now extremely large and contains different approaches and models, see for instance the review paper by [Harris and Raviv, 1991] or [Myers, 2001].

Tradeoff theory versus pecking order theory. In Modigliani-Miller analysis, it is assumed that there is no default risk and no corporate income tax. As long as there is a positive corporate income $\operatorname{tax} \tau_{a x}$, the sum of revenues perceived by shareholders and bondholders is now equal to $C+(\operatorname{EBIT}-C)\left(1-\tau_{a x}\right)=\operatorname{EBIT}\left(1-\tau_{a x}\right)+\tau_{a x} C$ and is an increasing function of $C$ due to the tax-shield effect. However, when $C$ is too large, default risk increases so that the (expected) cost of financial distress also increases. Within this approach, called the tradeoff theory, the optimal capital structure (that results from the coupon that maximizes the value of the firm) is the best tradeoff between the tax advantage of the debt and the cost of possible financial distress. But this is only one possible explanation. Another approach, perhaps simpler, is called the pecking order theory and says basically that the firm will make use of debt when internal cash flow is not enough to finance the investment project. As the name suggests, the pecking order theory of capital structure leads to an order. Firms prefer internal to external finance but if external funds are needed to finance the investment project, the firm should issue debt before equity (see [Myers, 2001] for more on this subject).

Agency costs of debt. In the Modigliani-Miller world, it is implicitly assumed that there is no conflict of interest between the various stakeholders, in part because the investment policy of the firm is given. The only problem consists in choosing the financing policy, that is, debt, equity or both. However, in practice, there are potentially various conflicts of interest between managers, bondholders and shareholders precisely because the investment policy is not given. For instance, when an investment project is essentially financed with debt, due to limited liabilities, shareholders have an incentive to choose a project which is riskier than the one they would choose if the project was financed with equity only. This phenomenon is known in the literature as the asset substitution problem (see [Harris and Raviv, 1991], section I for more on this subject). An important body of literature on agency cost (in line with capital structure) began with the seminal paper by [Meckling and Jensen, 1976], in which the optimal capital structure of the firm is obtained by trading off the agency cost of debt against the benefit of debt. We refer the reader to the review theory papers by [Harris and Raviv, 1991] and [Myers, 2001] but also to the chapter two of [Tirole, 2010]. It should be noted to conclude that, as observed in [Myers, 2001], there is no universal theory of capital structure and even no reason to expect one.

\section{Banks' capital requirements and channels of adjustment.}

The vast majority of the literature on capital structure is devoted to non-financial firms and 
thus excludes financial institutions such as banks. However, banks are of particular interest not only because they are financial institutions, that is, with a particular balance sheet (securities both appear on the asset and liability side) but also because they are heavily regulated, which means that they are not allowed to freely choose their capital structure. Since the asset side of the banks' balance sheet is essentially composed with securities (subject to market risk and/or to counterparty risk) and loans (subject to credit risk), equity (or capital) is designed to absorb the asset losses as a going concern, that is, without impeding the usual activity of the bank. Regulators thus impose a minimal percentage of the banks' activities that must be financed with equity. After the 2008 financial crisis, to take into account the deficiencies of Basel I and II, the Basel Committee on Banking Supervision ${ }^{3}$ (BCBS) published a document known as Basel 3, designed to strengthen the global capital framework. The BCBS makes a distinction between two types of capital, Tier 1 capital (going-concern capital), which is the sum of Common Equity Tier 1 (CET1) and additional Tier 1 (AT1) and Tier 2 (gone-concern capital). Beyond the classical risk-based capital ratios (e.g., Tier 1 divided by the risk-weighted assets (RWA)) now subject to various buffers (capital surcharge), the BCBS also introduced a new risk-unweighted capital ratio called the leverage ratio, defined as Tier 1 capital divided by the total exposure (a quantity which turns out to be close to the total assets). In 2023, banks will have to comply two Tier 1 capital ratios, the Tier 1 risk-based capital and the leverage ratio.

Assume now that a bank wants to increase its Tier 1 capital ratio because its current capital ratio is lower than its target capital ratio. What are the channels of adjustment that can be used? Following [Cohen and Scatigna, 2016], there are four main channels of adjustment that can be used by a bank to increase its risk-based capital ratio. Two channels are related to the liability side while the two others are related to the asset side.

1. The bank may increase over time its retained earnings by reducing its dividend policy (liability side). Progressively, everything else equal, the capital of the bank (Tier 1) as well as its Tier 1 capital ratio will increase.

2. The bank can issue new equity at one point in time (liability side). Right after this new issue, the capital (Tier 1 ) and thus the Tier 1 capital ratio of the bank will increase. Everything else equal, Tier 1 capital of the bank as well as its Tier 1 capital ratio will increase.

3. The bank can sell a portion of its loan portfolio and use the proceeds to pay back its debt (asset side). Everything else equal, Tier 1 capital of the bank as well as its Tier 1 capital ratio will increase.

4. The bank can reduce its risk-weighted assets by replacing riskier assets with safer ones (asset side). Everything else equal, the risk-weighted assets will decrease so that the capital ratio will also increase.

\footnotetext{
${ }^{3}$ In December 2017, the BCBS published a document entitled Basel 3 Finalising post-crisis reforms. The complete document called the Basel framework is available since December, 2019.
} 
Note importantly that the first three channels of adjustment both increase the risk-based capital ratio and the leverage ratio. However, by replacing assets with high risk weights by assets with low risk weights, this adjustement will not contribute to increase the leverage ratio as long as the the total value of the risky assets remains identical.

In a crisis period, that is, when say the overall banking sector has been hit by a common shock, as in 2007-2008, issuing equity will be very expensive while cutting the dividend policy will take many years to increase the capital ratio. After such a shock, banks typically choose to adjust their asset side and quickly deleverage in order to increase their capital ratio, something which is acknowledged by the Basel Committee. In [BCBS, 2015] (see Graph 1 p. 9), they explicitly consider the case in which a bank may deleverage by selling tradable securities to increase its risk-based capital ratio and/or may cut-off balance sheet exposure to increase its leverage ratio. The reason for this choice of channel of adjustment is related to the well-known debt Myers (1977) overhang problem ${ }^{4}$. After a shock, a bank may be reluctant to raise new equity to fund its (profitable) investments because an important portion of the value created will then be siphoned off by senior creditors of the bank ([Hanson et al., 2011]). In such a debt overhang situation, by acting in the interest of shareholders, the bank will shrink its assets rather than issue new equity. When many banks deleverage by selling assets or by replacing risky assets with safe ones, this leads to a generalized asset shrinkage that is costly for the society. As observed in (([Hanson et al., 2011]), the two primary costs are credit crunch (that is, banks may stop their lending activity and this can lead to an economic recession) and fire sales (that is, the price of the securities sold may sharply decrease). Interestingly and perhaps not so surprisingly, [Kapan and Minoiu, 2018] find that during the 2007/2008 financial crisis, banks with ex ante higher level of Tier 1 capital were able to maintain their credit supply when hit by a shock. [Brunnermeier, 2009] explains in detail the various origins of fire sales during the financial crisis and the vicious circle they generate. When asset prices fall, banks' capital ratio erodes and leads to fire sales to restore back their capital ratio which in turn push down the price and so on and so forth (see also [Braouezec and Wagalath, 2019] for a game theoretic equilibrium approach). These two costs for the society, credit crunch and fire sales, justify the implementation of a macro prudential regulation, which is by definition system-wide focused, and complements the micro prudential regulation, which is bank-by-bank focused. This macro prudential regulation leads to various capital buffers which in turn leads to higher capital requirements.

In [Gropp et al., 2019], the aim is precisely to inquire how banks adjust their balance sheets in response to higher capital requirement to understand the real consequence of these higher requirements. The authors exploit the 2011 capital exercise conducted by the European Banking Authority (see also [Greenwood et al., 2015]) and use a sample of 61 banks that were selected based on their total assets. Their main result is to show that banks decided to decrease their risk-weighted assets (by 16 percentage points) rather than to increase the capital by issuing new equity. More specifically, they show that banks reduced their exposure to corporate and retail borrowers. According to the authors, this lack of incentive to issue new equity can be partly explained by the debt overhang

\footnotetext{
${ }^{4}$ See Myers, S. C. (1977). Determinants of corporate borrowing. Journal of financial economics, 5(2), $147-175$.
} 
problem. In a related paper, [Bostandzic et al., 2018] also consider the EBA capital exercise as of 2011. Their results are consistent with the one [Gropp et al., 2019] in that they find that banks reduced their risk-weighted assets. Interestingly, they also use several (market) risk measures such as the Value-at-Risk, the expected shortfall or SRISK and all have increased, which suggests that the EBA capital exercise failed to increase bank solvency. In [Juelsrud and Wold, 2020], they consider a sample of 110-120 Norvegian banks and exclude foreign banks but also the second largest Norvegian bank Nordea (see also [Shimizu, 2015] for Japonese banks). An interesting feature of this article is that Norway is not a member of the EU. In Norway, the increase in capital requirements was proposed in March 2013 (and adopted in July 2013) and this new requirement was phased in over two years. Assuming that 2013 Q2 is the reform quarter, they document that banks increased their capital ratio by reducing the risk-weighted assets (through a reduction in credit supply), an empirical result which is consistent with [Gropp et al., 2019] and [Bostandzic et al., 2018]. In [Mayordomo and Rodríguez-Moreno, 2020], using a somewhat larger sample of 144 banks and with more recent data (i.e., from 2013 to 2017), they also show that the main channel through which banks increase their risk-based capital ratio is the risk reduction, that is, by rebalancing portfolios toward assets with lower risk-weights. Using a smaller sample of 35 banks but data from 2000 to 2016, [Klinac and Ercegovac, 2018] document a similar result, banks adapted to the new regulation by decreasing their credit (risk) exposure.

Overall, these recent papers provide evidence that the main channel of adjustment used by banks to increase their capital ratio is the asset side, either by reducing the exposure to risky assets or by rebalancing their portfolios toward safer assets.

\section{A simple model of target capital ratio with costly channels of adjustment}

We offer here a simple model for which the parameters are easy to calibrate using public data. We consider the case of a systemic universal bank which is subject to the (evolving) Basel regulation and that holds three types of assets that differ by their riskiness and their liquidity.

1. A safe asset, cash, which is the value of the bank account of the bank at the central bank. Cash is not risky and is thus not subject to capital requirement.

2. A risky traded asset such as a stock, an Exchange Traded Fund (ETF), a bond, (possibly a derivative) for which some capital is required because it is both subject to market risk and counterparty risk.

3. A set of non-traded loans for which capital is required because they are subject to credit risk.

Banks hold loans in their banking book for a non-negligible fraction (at least $30 \%$ of the total value of the assets) and also hold liquid traded assets in their trading book (stocks, bonds, ETF, derivatives). Due to the well-known adverse selection problem (e.g., [Diamond and Rajan, 2011]) 
loans are illiquid assets and thus are fairly difficult to resell in the short-term. Since we are interested to understand the conditions under which a bank will optimally issue new shares only, considering a model with more than one risky asset would only contribute to complicate the analysis without new financial insights. For the sake of simplicity, as in [Admati et al., 2018] (see their proposition 7), we thus focus on the simplest model in which there is a unique homogenous risky traded asset subject to capital requirements. Of course, the bank can also invest in a risk-free asset, its bank account at the central bank, which is thus not subject to capital requirement. In section 4 devoted to the empirical applications, we shall relax this assumption and we will explicitly consider the case of two risky assets, a liquid one and an illiquid one. We shall show that as long as the resale value of this illiquid asset is sufficiently small, nothing is fundamentally changed.

\subsection{Bank's balance sheet and target capital ratio}

Let $v>0$ be the value of cash at time $t=0$ and let $P$ and $q$ denote respectively the price (or the Mark-to-Market more generally) and the quantity of the risky asset held by the bank at date $t=0$. The total value of the assets of the bank at time $t=0$ is equal to $A=v+q P$. On the liability side, let $D$ be the sum of deposits and total face value of bonds that have been issued by the bank. Let $E$ denotes the capital of the bank at time $t=0$. From limited liability of shareholders, the value of total equity at date $t=0$ is equal to $E=\max \{A-D ; 0\}=\max \{v+q P-D ; 0\}$ and we shall assume that this total capital is positive at time $t=0$, that is

$$
E=v+q P-D>0
$$

The total capital $E$ is equal to Tier 1 capital $K_{1}$ plus Tier 2 capital $K_{2}$, that is $E=K_{1}+K_{2}$. To facilitate the presentation, without loss of generality, we shall assume that $E=K_{1}$. This assumption is realistic in practice since the most important component of the total capital is by far Tier 1 capital. In any event, it is not difficult from a theoretical point of view to assume that Tier 2 capital is positive. As we shall see, the advantage of this assumption is that the target capital

ratio can be formulated directly by using $E$ rather than a fraction of $E$ equal to $\frac{K_{1}}{E}$. The following balance-sheet represents the situation of the bank at time $t=0$.

Balance sheet at time $t=0$

\begin{tabular}{|c|c|}
\hline Assets & Liabilities and Equity \\
\hline Cash: $v$ & Debt: $D$ \\
Risky asset: $q P$ & Equity $: E$ \\
\hline$A=v+q P$ & $E+D$ \\
\hline
\end{tabular}

Since there is only one risky asset, the risk-weighted asset (RWA) can thus be expressed as a percentage of the value of the risky asset $q P$. As cash is considered as risk-free by regulators, its weight is equal to zero and thus is not subject to any capital requirement. The risk-weighted assets thus is equal to

$$
\mathrm{RWA}=\alpha q P
$$


where $\alpha<1$ is the risk-weight associated to the risky asset. Since all the quantities involved, i.e., cash, the value of the risky assets and the risk-weighted assets are disclosed in the annual report of banks, $\alpha$ is easy to calibrate and is equal to

$$
\alpha=\frac{\text { RWA }}{q P}
$$

Let

$$
\theta=\frac{v+q P-D}{\mathrm{RWA}}=\frac{K_{1}}{\alpha q P}
$$

be the regulatory capital ratio of the bank at time $t=0$ and let respectively $\theta_{\min }$ and $\theta^{*}$ be the minimum capital ratio and the target capital ratio. For the sake of interest, we shall assume that

$$
\theta_{\min } \leq \theta<\theta^{*}
$$

that is, the current capital ratio is lower than the target capital ratio but is higher than the minimum required. The quantity defined as $\theta^{*}-\theta_{\min }>0$ can be interpreted as a safety spread (or margin). For the sake of interest, one may assume that at the current date, $\theta=\theta_{\min }$ so that there is no safety margin.

In the Basel framework, another capital ratio, called the leverage ratio will complement the classical risk-based capital ratio. The striking feature of this leverage ratio is that it is a risk unweighted capital ratio defined as Tier 1 capital divided by the total exposure, a quantity close to the total assets. According to a document from the European Systemic Risk Board (ESRB)

"The leverage ratio increases the resilience of large, complex and interconnected institutions against higher model risk and uncertainty. Given that large and complex institutions are more likely to rely on internal rating-based approaches to set risk-weighted assets capital requirements and to have significant trading books with low measured risk, they are also more likely to be influenced by both model risk and uncertainty". ([(ESRB), 2015] p. 6)

In practice, the leverage ratio is intended for (large) banks that make use of internal models and is designed to serve as a backstop against an average implied risk-weight that would be artificially low ([BoE, 2017]). Within our simple model, we shall proxy the total exposure by the total value of the risky asset $q P$. As a result, the leverage ratio is defined as

$$
L=\frac{E}{q P}=\frac{K_{1}}{q P}
$$

and must be greater than $L_{\text {min }}$, the minimum leverage ratio. The risk-based capital ratio and the leverage ratio turn out to be intimately related since they have the same numerator. The denominators are however different, it is the risk-weighted assets for the risk-based capital ratio and the total exposure for the leverage ratio. In practice, the requirements are also different since $L_{\min }$ 
is equal to $3 \%$ while $\theta_{\min }$ is approximately equal to $8.5 \%$. Within our framework, it is easy to see from equation (4) that

$$
\theta=\frac{L}{\alpha}
$$

that is, the leverage ratio and the risk-based capital ratio are equal up to the inverse of the implied risk-weight term equal to $\frac{1}{\alpha}$, something observed for instance in [(ESRB), 2015]. From an empirical point of view, the simple relation between the Tier 1 risk-based capital ratio and the leverage ratio (given in equation (7)) can be more complex since the value of the risky assets and the total exposure may not coincide. However, for most banks, total assets and total exposure do not differ by more than $5 \%$ and this means that equation (7) provides an accurate relation.

To understand why the leverage ratio acts as a backstop against an artificially low risk-weighted assets, we shall follow the presentation offered in [(ESRB), 2015] annex 1 and in [BoE, 2017]. Let $K_{1}^{\theta}=\theta_{\min } \alpha q P$ be the capital of the bank required by the risk-based capital ratio and $K_{1}^{L}=L_{\min } q P$ be the capital required by the leverage ratio. The leverage ratio and the risk-based capital ratio are said to be equally stringent when $K_{1}^{L}=K_{1}^{\theta}$, which is equivalent to an implied weight equal to $\alpha_{c}=\frac{L_{\min }}{\theta_{\min }}$ called the critical average risk weight. Note that since $\alpha_{c}$ depends upon $L_{\min }$ and $\theta_{\min }$ only, the critical threshold $\alpha_{c}$ is a quantity which is fixed by regulators.

Assume that $K_{1}^{L}>K_{1}^{\theta}$, that is, the capital required by the leverage ratio is greater than the capital required by the risk-based capital ratio. It is easy to show that this is equivalent to $\alpha<\alpha_{c}$ and it is precisely in that sense that the leverage acts as a backstop. When the implied risk-weight $\alpha$ is considered as "too low" by regulators, that is, lower than the critical average risk weight $\alpha_{c}$, the bank is constrained by the leverage ratio and not anymore by the risk-based capital ratio and it is in that sense that the leverage ratio acts as a backstop. It should be pointed out that the leverage ratio is currently (in 2020) disclosed in annual reports of banks but will be binding in principle in January, 2022, in practice in January 2023 due to Covid- $19^{5}$.

\subsection{Equity issuance versus asset sale: what are the costs?}

We have already seen in section 2 that there are four different (non-exclusive) ways through which a bank can increase its capital ratio. In this paper, we shall consider the two main channels of adjustment that can be used by a bank in the short term, equity issuance and/or asset sale (asset shrinking or risk-reduction). The bank can issue new equity with gross proceeds equal to $I>0$ or it can reduce its risk-weighted assets (RWA) by selling a portion $s \in[0, q]$ of the risky asset (with positive weights) and then investing the proceeds in cash (with no risk weight). Of course, the bank can also mix the channels, i.e., it can issue new shares (i.e, choose $I>0$ ) and sell a portion of the risky asset (i.e, choose $s>0$ ).

Consider first the possibility to issue new shares. While there are several flotation methods, i.e., various ways to issue such new shares (see e.g., [Eckbo et al., 2007] for a comprehensive review), we

\footnotetext{
${ }^{5}$ See https://www.bis.org/press/p200327.htm. Note also that systemic banks identified as such by the financial stability board will have a leverage buffer requirement as a function of the G SIB buffer.
} 
only mention the three following ones.

- Firm commitment, in which the set of underwriter(s) contractually commit to buy the new shares at a fixed price.

- Standby rights, in which existing shareholders are offered the right but not the obligation to buy the new shares at a discount and the set of underwriters are committed to buy the unexercised new shares.

- Direct public offering, in which the issuer sells directly the equity without any underwriters.

The issuance cost obviously depends on the choice of the flotation method. The cheapest one is clearly the direct public offering because the issuer has no guarantee to receive the desired gross proceeds while the most expensive one is the firm commitment.

In [Eckbo et al., 2007], they make a distinction between direct costs (e.g., underwriter(s) fees, registration and listing fees) and indirect costs (e.g., stock price reaction to the offering announcement, cost of offering delay/cancellations...). It is also common to split the total direct cost of issuance into two types of costs (see for instance [Altınkılıç and Hansen, 2000]); a fixed cost, related to various administrative costs (registration and listing fees) and a variable cost, related to the underwriter(s) compensation that critically depends upon the underwriting agreement and the gross proceeds. Since $P$ denotes the asset price, we shall denote $I$ the gross proceeds ( $I$ for investment) chosen by the bank. Following [Altınkılıç and Hansen, 2000], [Décamps et al., 2011] and [Gomes, 2001] among others, the total issuance cost function is assumed to be piece-wise linear:

$$
\text { Cost of equity issuance }=K \mathbf{1}_{I>0}+c I
$$

where $\mathbf{1}_{I>0}=1$ if $I>0$ (i.e., the bank issues new stocks) and $\mathbf{1}_{I>0}=0$ if $I=0, K$ is the fixed (issuance) cost and $c \in(0,1)$ is the (constant marginal) issuance cost. This means that when the bank decides to issue new equity for gross proceeds equal to $I$, it has to pay $K$ and $c I$, which means that the net amount of cash received by the bank, called the net proceeds, is equal to $(1-c) I-K$. For the net proceeds to be positive, $I$ must be high enough. The marginal cost $c$ is the sum of the two following marginal costs $m$ and $d$, that is, $c=m+d$ where

- $m$ is the marginal cost of issuance and is related as already said for instance to underwriters compensation and

- $d$ is the marginal cost of dilution assumed to linearly increase with $I$.

It should be noticed that the way dilution costs are encapsulated within our framework can be thought of as a reduced form approach. Dilution costs may be an issue when an institution decides to increase its capital. However, there is not a unique way to model these costs. Within our framework, when $K=c=0$ but when $d>0$, the cost of issuing equity is still positive due to the existence of dilution costs that are an increasing function of $I$. As we shall see in the empirical 
application, the right issue is precisely designed to avoid dilution for those shareholders who choose to exercise their rights.

It is usual to define the spread as the average cost of issuance per euro, i.e., it suffices to divide the rhs of equation (8) by the gross proceeds $I>0$ (e.g., [Altınkılıç and Hansen, 2000]).

$$
\text { Spread }=\frac{K}{I}+c \quad I>0
$$

For systemic banks, as we shall see, the gross proceeds $I$ is in billion while the fixed cost $K$ is in (hundreds) thousands so that $\frac{K}{I}$ is negligible. We thus make the assumption that $\frac{K}{I}=0$ so that $c$ is the unique cost of issuance. It is actually well-known that the important source of issuance cost is the variable cost (e.g., [Altınkılıç and Hansen, 2000], [Calomiris and Tsoutsoura, 2010]).

Consider now the costs associated with replacing (i.e., selling) riskier assets with safe ones such as cash (or Government bonds that are considered as risk-free) in order to decrease the risk-weighted assets. Let $s \in[0, q]$ be the quantity of the risky asset sold by the bank and $V(s)$ be the proceeds of the asset sale placed on the bank account of the bank (cash). Since the risk-weighted assets $\operatorname{RWA}(s)=\alpha P(q-s)$ is a decreasing function of $s$, everything else equal, the risk-based capital ratio of the bank will increase. For systemic banks, everything else is however not equal. Due to the existence of the price impact, the price of the risky asset will decrease with the quantity sold $s$ and this will decrease the value of the assets and thus the total capital of the bank. Moreover, selling a portion of the risky asset will also reduce the (future) expected profit.

Price impact. For a systemic bank, called G-SIB (global systemically important bank), selling an important volume of assets in a short period of time may generate a positive price impact. Following the seminal paper of [Greenwood et al., 2015], see [Duarte and Eisenbach, 2015], we consider the simplest case of a linear price impact. When the bank sells a quantity $s \leq q$ of the risky asset, the sale proceeds $V(s)$ is not equal to $s P$ but is lower due to the existence of a positive price impact. For a given price $P$ at time $t=0$, the price at time $t=1$ thus is equal to

$$
P\left(1-\frac{s}{\Phi}\right)
$$

where $\Phi<\infty$ is called the market depth. The lower (higher) the market depth, the more (less) important the price impact. With a linear price impact given by equation (10), the proceeds $V(s)$ is equal to $s P\left(1-\frac{s}{\Phi}\right)$ and we shall make the realistic assumption ${ }^{6}$ that $V(s)$ increases with the quantity sold $s \in[0, q]$, i.e., $\frac{2 q}{\Phi}<1$. The cost due to the price impact of the bank is naturally measured as the difference between the proceeds without price impact and the proceeds with a positive price impact. This cost thus is equal to $s P\left(\frac{s}{\Phi}\right)$ and increases with the quantity sold $s$. But this is not the only cost.

\footnotetext{
${ }^{6}$ We make the implicit assumption that when selling a portion of assets $s$, the price at which the bank can sell this quantity is equal to $P\left(1-\frac{s}{\Phi}\right)$. As [Braouezec and Wagalath, 2018] among others, a more dynamic way to take into account the price impact would be to assume that the bank liquidate in a uniform way its assets from time zero to one and sells at the average price equal to $P\left(1-\frac{s}{2 \Phi}\right)$
} 
Reduction of the expected profit. Even without price impact, there is a cost associated to selling the risky asset, related to the fact that the expected profit will decrease with $s$. Assume that the expected profit is equal $\mathbb{E} \Pi(q)=\gamma q P$ (for some $\gamma<1$ and some expectation operator $\mathbb{E}$ ) when the bank holds a quantity $q$ of the risky asset, that is, the expected profit is a percentage of the total value of the position in the risky asset. When the bank resells a positive quantity $s$, it now holds a quantity $q-s$ and the resulting expected profit is equal to $\mathbb{E} \Pi(q-s)=\gamma P(q-s)=\mathbb{E} \Pi(q)-\gamma P s$. Compared with the initial situation in which the bank held a quantity $q$, when it sells a quantity $s \leq q$, the reduction of its expected profit thus is equal to $\gamma s P$, which constitutes the second opportunity cost of selling a portion of the risky asset. In the limiting case in which $s=q$, the bank only holds cash and the expected profit thus is equal to zero ${ }^{7}$. Overall, the cost of selling the risky asset is the cost related to the price impact plus the reduction of the expected profit.

$$
\text { Cost of selling the risky asset }=s P\left(\gamma+\frac{s}{\Phi}\right)
$$

We make the natural assumption that the aim of the bank is to choose the channel(s) of adjustment in order minimize the sum of the adjustment costs given by equation (8) plus equation (11).

In the rest of this section, we shall state and solve the optimization problem of the bank as a function of the parameters. We make the assumption that the adjustment is instantaneous, that is, once the bank has chosen the channel(s) of adjustment, there is no delay for the implementation. In the empirical literature on partial adjustment (see e.g., [Flannery and Rangan, 2006] or [Öztekin and Flannery, 2012]) they make the assumption that there is a delay, that is, using our notations, the partial adjustment model for a given firm is written as $\theta_{t}-\theta_{t-1}=\lambda\left(\theta^{*}-\theta_{t-1}\right)+\epsilon$ where $\lambda$ is the adjustment speed and $\epsilon$ is a noise term. Taking into account such an adjustment speed in an optimization model would be more difficult from a mathematical point of view since it would require to solve a dynamic optimization problem. It would also be more difficult to test assuming even that it yields clear predictions. Overall, we believe that the (purely) empirical partial adjustment literature and the static (optimization-based) model offered in this paper are complementary rather than substitutable. Since our static model yields clear prediction as a function of the observable) parameters, this prediction can be tested on a bank by bank basis. It is interesting to note that in the empirical partial adjustment models, the target is not assumed to be observable. On the contrary, within our approach, we explicitly use the fact that the target capital ratio $\theta^{*}$ is explicitly disclosed in annual reports of banks.

\footnotetext{
${ }^{7}$ In Europe, the profit would actually be negative since the rate of the deposit facility administered by the ECB is negative, equal to $-0.5 \%$. The rate of the deposit facility is the interest which is applied by the ECB when a given bank leaves its excess reserves on its bank account at the ECB. Since 30, October, 2019, there is a two tier system which "exempts credit institutions from remunerating, at the negative rate currently applicable on the deposit facility, part of their excess reserve holdings (i.e. reserve holdings in excess of minimum reserve requirements"). See the website of the ECB, https://www.ecb.europa.eu/mopo/two-tier/html/index.en.html
} 


\subsection{The bank's optimization problem}

For a given choice of channel(s) of adjustment $(s, I) \in[0, q] \times \mathbb{R}^{+}$, the bank's balance-sheet at date $t=1$ is given as follows:

Balance sheet at time $t=1$

\begin{tabular}{|c|c|}
\hline Assets & Liabilities and Equity \\
\hline Cash: $v+s P\left(1-\frac{s}{\Phi}\right)+(1-c) I$ & $D$ \\
Risky asset: $(q-s) P\left(1-\frac{s}{\Phi}\right)$ & $E(s, I)$ \\
\hline$A(s, I)=v+q P\left(1-\frac{s}{\Phi}\right)+(1-c) I$ & $E(s, I)+D$ \\
\hline
\end{tabular}

and note that the total capital at time $t=1, E(s, I)=\max \{A(s, I)-D ; 0\}$, depends on $(s, I)$ while the risk-weighted assets RWA $(s)$ depends only on $s$. Formally, the bank's optimization problem is as follows.

$$
\begin{aligned}
& \min _{(s, I) \in[0, q] \times \mathbb{R}_{+}} C(s, I)=s P\left(\gamma+\frac{s}{\Phi}\right)+c I \\
& s / c \\
& \theta(s, I):=\frac{E(s, I)}{\operatorname{RWA}(s)}=\frac{v-D+q P\left(1-\frac{s}{\Phi}\right)+(1-c) I}{\alpha(q-s) P\left(1-\frac{s}{\Phi}\right)}=\theta^{*} \\
& L(s, I):=\frac{E(s, I)}{A(s, I)-v}=\frac{v-D+q P\left(1-\frac{s}{\Phi}\right)+(1-c) I}{(q-s) P\left(1-\frac{s}{\Phi}\right)} \geq L_{\text {min }} \\
& s \geq 0, I \geq 0
\end{aligned}
$$

Note importantly that we make the assumption that the bank uses the risk-reduction strategy, that is, the bank sells a portion of its risky assets (with a positive risk weight) and invests the proceeds in reserves (that is, put the amount on its bank account at the central bank), which is an asset with no risk weight. Another solution for the bank is to use the asset shrinking strategy, that is, it also consists to sell a portion of the risky assets and to use the proceeds to pay back a portion of its debt.

Fact 1 Whether the bank uses the risk-reduction strategy or the asset shrinking strategy, the two capital ratios given by equations (13) and (14) remain identical.

The proof of this result is very simple. When the bank sells a quantity $s$ of risky asset whose value is equal to $s P$, the proceeds are equal to $s P\left(1-\frac{s}{\Phi}\right)$ due to the price impact. Since the bank uses this amount to repay the debt, the value of the debt is reduced to $D-s P\left(1-\frac{s}{\Phi}\right)$ but all the other quantities except the total assets $^{8}$ remain unchanged, in particular the risk-weighted assets and the capital so that the two capital ratios given by equations (13) and (14) remain identical and this concludes the proof.

\footnotetext{
${ }^{8}$ When the bank replaces the risky asset by the non-risky one, the value of the total assets is equal to $v+q P(1-$ $\left.\frac{s}{\Phi}\right)+(1-c) I$ while it is equal to $v+(q-s) P\left(1-\frac{s}{\Phi}\right)+(1-c) I$ when the bank repays a portion of its debt.
} 
Let $\left(s^{*}, I^{*}\right) \in[0, q] \times \mathbb{R}^{+}$be the optimal solution when it exists and note that it must be such that $s^{*}<q$ otherwise, the denominator of the capital ratio is equal to zero. Recall that it is assumed that $E=K_{1}$.

Proposition 1 Assume that $L \geq L_{\text {min }}, \theta=\theta_{\text {min }}$ and $\theta^{*}>\theta_{\text {min }}$. If there exists an optimal solution $\left(s^{*}, I^{*}\right) \in[0, q) \times \mathbb{R}^{+}$such that $\theta\left(s^{*}, I^{*}\right)=\theta^{*}$, then, $L\left(s^{*}, I^{*}\right) \geq L_{\text {min }}$

The above result shows that as long as the target capital ratio can be reached under the optimal solution, then, if the leverage ratio was satisfied at time $t=0$, it is automatically satisfied at time $t=1$. To see this, recall that we make the assumption that $\theta=\theta_{\min }$ so that $\alpha=\frac{L}{\theta_{\min }}$. Since $\theta\left(s^{*}, I^{*}\right)=\frac{L\left(s^{*}, I^{*}\right)}{\alpha}$, by using the fact that $\alpha=\frac{L}{\theta_{\min }}$ and that $\theta\left(s^{*}, I^{*}\right)=\theta^{*}$, we obtain that $L\left(s^{*}, I^{*}\right)=L \times\left(\frac{\theta^{*}}{\theta_{\min }}\right) \geq L_{\min }$ since $L \geq L_{\min }$ and $\left(\frac{\theta^{*}}{\theta_{\min }}\right)>1$. If $\theta>\theta_{\min }$, then, for some positive $\zeta, \alpha$ can be written as $\alpha=\frac{L}{(1+\zeta) \theta_{\text {min }}}$. Everything else equal, the higher $\theta-\theta_{\text {min }}$, the higher $\zeta$. By definition of a target capital ratio, the current capital ratio $\theta$ is lower than $\theta^{*}$ and rather close to the minimum required $\theta_{\text {min }}$. If $\theta$ is much greater than $\theta_{\text {min }}$, specifying a target makes no real sense. This means that $\zeta$ is close to one and as a consequence $\frac{\theta^{*}}{(1+\zeta) \theta_{\min }} \geq 1$ so that $L\left(s^{*}, I^{*}\right)=\alpha \theta^{*}=L \frac{\theta^{*}}{(1+\zeta) \theta_{\min }} \geq L_{\text {min }}$, that is, proposition 1 holds. Proposition 1 thus still holds when $\theta>\theta_{\min }$ as long as, everything else equal, $\theta$ remains close to $\theta_{\min }$. So far, we make the assumption in proposition 1 that there is indeed an optimal solution $\left(s^{*}, I^{*}\right)$. We shall now discuss the condition under which such an optimal solution exists.

Consider first the case in which there is no price impact, i.e., $\frac{1}{\Phi}=0$. In such a case, since the total value of the assets as well as the total equity are invariant with respect to $s \in[0, q]$, a solution always exists in $s$ (i.e., with $I=0$ ) for each $\theta^{*} \in \mathbb{R}^{+}$. When the price impact is positive, the total value of the assets as well as the total capital of the bank are now decreasing functions of $s \in[0, q]$. As a result, a solution of the optimization problem in $s$ only (i.e., with $I=0$ ) may not always exist; reaching the target capital ratio may thus require from the bank to use the two channels of adjustment, i.e., asset sale and/or new issues. When the price impact is small enough, i.e., when $\frac{1}{\Phi}$ is close enough to zero, a solution always exists. Let $E(q, 0)=v-D+q P\left(1-\frac{q}{\Phi}\right)$ be the total capital at time $t=1$ when the bank sells $100 \%$ of its risky asset and does not issue new shares. It is easy to show that

$$
E(q, 0)>0 \Longleftrightarrow \frac{q}{\Phi}<\frac{v+q P-D}{q P}
$$

Let $\underline{\Phi}=\frac{q^{2} P}{v+q P-D}$ and note that $\Phi>\underline{\Phi}$ is equivalent to $E(q, 0)>0$. When $\Phi>\underline{\Phi}$, a solution in $s<q$ always exists to reach the target capital ratio but it turns out that the risk-based capital ratio $\theta(s, 0)$ may not be an increasing function of $s$ for each $s \in[0, q]$. In appendix, we show the existence of a smallest market depth $\bar{\Phi}$ (greater than $\underline{\Phi}$ ) such that, when $\Phi>\bar{\Phi}$, the risk-based capital ratio $\theta(s, 0)$ is an increasing function of $s$ for each $s \in(0, q)$. While the existence of a solution only requires $\Phi>\underline{\Phi}$, we shall assume that $\Phi>\bar{\Phi}$ to avoid the somewhat pathological behavior of the risk-based capital ratio which may be locally decreasing with $s$. 
Proposition 2 (Existence of corner solutions)

- Assume that $s=0$. If $c<1$, then, for any $\theta^{*} \in \mathbb{R}^{+}$, there exists a unique $\bar{I}\left(\theta^{*}\right)$ such that $\theta\left(0, \bar{I}\left(\theta^{*}\right)\right)=\theta^{*}$

- Assume that $I=0$. If $\Phi>\bar{\Phi}$, then, for any $\theta^{*} \in \mathbb{R}^{+}$, there exists a unique $\bar{s}\left(\theta^{*}\right)$ such that $\theta\left(\bar{s}\left(\theta^{*}\right), 0\right)=\theta^{*}$.

Proof. See the appendix.

The above proposition shows that under rather mild assumptions, the bank is able to reach its target capital ratio by issuing new shares only or by selling a portion of the risky asset only.

\subsection{Small banks, large banks and the optimal channel(s) of adjustment}

In Europe, since few years, the European Banking Authority (EBA) provides a list of large institutions, defined as banks with an exposure measure higher than 200 billion (euros). In 2019, this list contains 36 banks and 11 are currently identified as Global Systemically Important Banks (GSIBs). For instance, in France, four banks are identified as G-SIBs while in Germany and Italy, only one bank is identified as G-SIB, Deutsche Bank and Unicredit respectively. For such G-SIBs, the exposure measure is higher than 1000 billion (euros). As a result, when a G-SIB sells an important fraction of its total assets (say to reach its target capital ratio), the price impact is not negligible. On the contrary, for small banks, the price impact will be negligible and can be assumed equal to zero, that is, $\frac{1}{\Phi}=0$.

In what follows, we first consider the case in which there is no price impact (i.e., small banks), that is, $\frac{1}{\Phi}=0$. In such a situation, it is easy to see that the optimization program (12) subject to the constraints given by equations (13) and (15) reduces to a linear programming problem. As a result, the optimal strategy is a corner solution, that is, either $\left(0, I^{*}\right)$ or $\left(s^{*}, 0\right)$. In particular, it is never optimal to both issue new stocks and sell a portion of the risky asset. We then consider the case of large banks such as G-SIBs for which the price impact is positive, that is, $\frac{1}{\Phi}>0$. In such a case, this leads to a non-linear programming problem due to the presence of the price impact and it may be optimal for the bank to both issue new stocks and sell the risky asset. In both cases, i.e., with and without price impact, to facilitate the confrontation with observed data, we formulate the solution of the optimization problem in terms of critical spreads. In the no price impact case, there is a single critical spread that we denoted $c_{u}$, where $u$ simply means unique or uniform. In the price impact case, there will be two critical spread that we shall denote $c_{l}$ and $c_{h}$ where $l$ and $h$ means as usual low and high.

Proposition 3 (Small banks, linear programming problem)

Assume that $\frac{1}{\Phi}=0$ (i.e., no price impact) and let

$$
c_{u}=\frac{\gamma}{\gamma+\alpha \theta^{*}}
$$


be a critical spread. The optimal channel of adjustment is as follows.

- When $c<c_{u}, s^{*}=0$ and $I^{*}=\frac{\theta^{*} \alpha q P-E}{1-c}$, that is, it is optimal for the bank to issue equity only.

- When $c>c_{u}, s^{*}=q-\frac{E}{\alpha P \theta^{*}}$ and $I^{*}=0$, that is, it is optimal for the bank to only sell a portion of the risky asset.

Proof. See the appendix.

From the above proposition, when $\gamma$ tends to zero, the cost of selling the risky asset also tends to zero since there is no price impact. As a result, the critical spread $c_{u}$ tends to zero and it becomes highly likely that selling the risky asset will constitute the optimal channel of adjustment. From equation (17), when $\alpha$ tends to zero, the critical spread tends to one so that it becomes optimal to issue new equity only. This property comes from the fact that $\frac{\partial s^{*}}{\partial \alpha}>0$, that is, the optimal quantity of risky asset to sell is an increasing function of $\alpha$. Since $s^{*}$ is negative when $\alpha$ is small enough, there exists $\bar{\alpha}>0$ such that $s^{*}=0$ for each $\alpha$ lower than $\bar{\alpha}$. The non-negativity of $s^{*}$ comes from equation (15). From an empirical point of view, this property suggests that banks with a low $\alpha$ are more likely, everything else equal, to issue new equity when there is no price impact. In the same vein, when the target $\theta^{*}$ decreases (increases), everything else equal, banks are more (less) likely to issue new shares since the critical spread increases (decreases) and tends to one.

We now come to the main result of our article and prove the existence and uniqueness of an optimal channel of adjustment in the general case, that is a solution to the optimization problem defined by equations (12) to (15). Consider Fig.1 and let us call iso-target curve the subset of points defined as follows

$$
\Theta^{*}=\left\{(s, I) \in\left[0, \bar{s}\left(\theta^{*}\right)\right] \times\left[0, \bar{I}\left(\theta^{*}\right)\right]: \theta(s, I)=\theta^{*}\right\}
$$

From proposition 2, when $s=0$, the target can be reached by choosing $\bar{I}\left(\theta^{*}\right)$ while when $I=0$, the target can be reached by choosing $\bar{s}\left(\theta^{*}\right)$. As both $s$ and $I$ can be positive, $\Theta^{*}$ provides the set of choices of $s$ and $I$ such that the target is reached. As one may expect, the marginal rate of substitution between the gross proceeds and the quantity of risky asset sold is negative. Starting from a given point $(s, I) \in \Theta^{*}$, if the bank decides to slightly increase the quantity sold from $s$ to $s+\delta s$, it can thus decrease the gross proceeds from $I$ to $I-\delta I$ for some positive $\delta I$. In appendix, we show that the iso-target curve (i.e., the constraint) is a decreasing and strictly convex function of $s$ while an iso-cost curve is a decreasing and strictly concave function of $s$. The optimization problem thus is well-behaved in that when it is optimal to mix the channel of adjustment, i.e., $s^{*}>0$ and $I^{*}>0$, this optimal solution is found by using a classical tangency condition, see Fig. 1. Depending upon the parameters of the model $\alpha, \gamma, c, \theta^{*}$, with $\frac{1}{\Phi}>0$, the optimal solution belongs to one (and only one) type of the three types of solutions below.

$$
\underbrace{s^{*}=0 \text { and } I^{*}>0}_{\text {Issue only }} \text { or } \underbrace{s^{*}>0 \text { and } I^{*}>0}_{\text {Mix }} \text { or } \underbrace{s^{*}>0 \text { and } I^{*}=0}_{\text {Sell only }}
$$




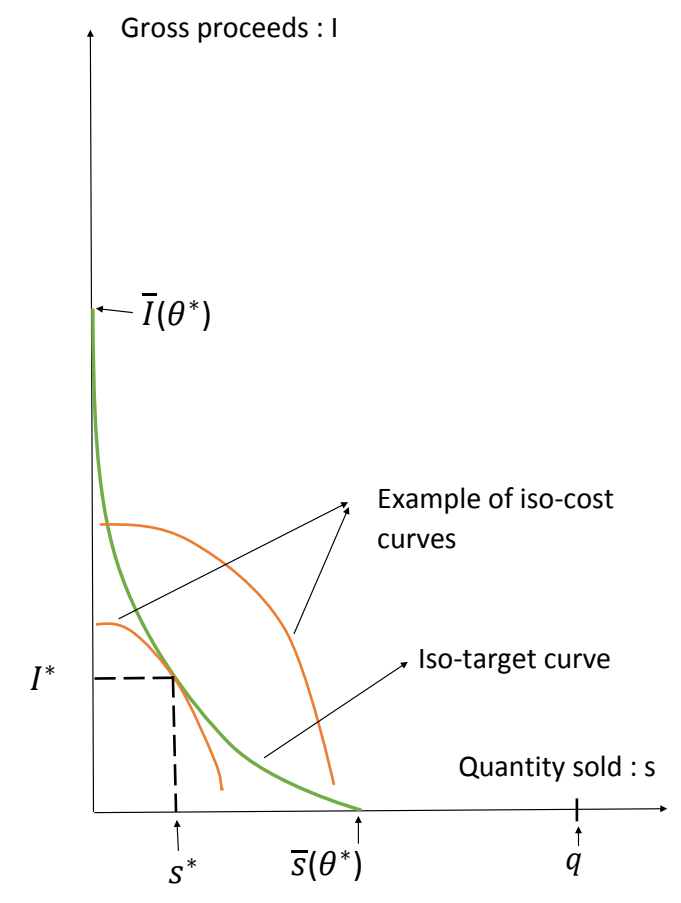

Figure 1: Optimal solution: $s^{*}>0$ and $I^{*}>0$

On Fig. 1, we represent the unique solution $s^{*}>0$ and $I^{*}>0$ of the optimization problem, which implies for the bank to make use of the two channel of adjustment, asset sale and stock issuance so that $s^{*}>0$ and $I^{*}>0$ can be found using a classical tangency condition. The next proposition provides a characterization of the optimal solution in terms of two thresholds.

Proposition 4 (Large banks, non-linear programming problem)

Assume that $\frac{1}{\Phi}>0$ and that $\Phi \geq \bar{\Phi}$. There exists a couple of critical spreads $\left(c_{l}, c_{h}\right) \in(0,1)^{2}$ with $c_{l}<c_{h}$ such that the optimal channel of adjustment is as follows:

- When $c<c_{l}$, the bank will issue equity only so that $s^{*}=0$ and $I^{*}=\bar{I}\left(\theta^{*}\right)=\frac{\alpha q P \theta^{*}-E}{1-c}$

- When $c \in\left(c_{l}, c_{h}\right)$, the bank will both sell a positive portion of the risky asset $s^{*}>0$ and issue new equity $I^{*}>0$ with $\left(s^{*}, I^{*}\right)$ equal to

$$
\begin{aligned}
s^{*} & =\frac{\left(\alpha \theta^{*}\left(1+\frac{q}{\Phi}\right)+\gamma-\frac{q}{\Phi}\right) c-\gamma}{\frac{2}{\Phi}\left(\alpha \theta^{*}-1\right) c+\frac{2}{\Phi}} \\
I^{*} & =\frac{1}{1-c}\left(\theta^{*} \alpha\left(q-s^{*}\right) P\left(1-\frac{s^{*}}{\Phi}\right)-E+\frac{q P s^{*}}{\Phi}\right)
\end{aligned}
$$

- When $c>c_{h}$, the bank will sell the risky asset only so that $s^{*}=\bar{s}\left(\theta^{*}\right)$ and $I^{*}=0$ with 


$$
\begin{aligned}
\bar{s}\left(\theta^{*}\right) & =\frac{\alpha P \theta^{*}\left(1+\frac{q}{\Phi}\right)-\frac{q P}{\Phi}-\sqrt{\Delta}}{\frac{2 \alpha P \theta^{*}}{\Phi}} \\
\Delta & =\left(\alpha P \theta^{*}\left(1+\frac{q}{\Phi}\right)-\frac{q P}{\Phi}\right)^{2}-4 \frac{\left(\alpha P \theta^{*}\right)^{2} q}{\Phi}\left(1-\frac{\theta}{\theta^{*}}\right)
\end{aligned}
$$

The critical spreads $\left(c_{l}, c_{h}\right)$ have the following expression:

$$
\begin{aligned}
c_{l} & =\frac{\gamma}{\gamma+\alpha \theta^{*}-\frac{q}{\Phi}\left(1-\alpha \theta^{*}\right)} \\
c_{h} & =\frac{\gamma+\frac{2}{\Phi} \bar{s}\left(\theta^{*}\right)}{\gamma+\alpha \theta^{*}-\frac{q}{\Phi}\left(1-\alpha \theta^{*}\right)+\frac{2}{\Phi} \bar{s}\left(\theta^{*}\right)\left(1-\alpha \theta^{*}\right)}
\end{aligned}
$$

Proof. See the appendix.

Recall that we make the assumption that the capital ratio is an increasing function of the quantity sold, that is, $\Phi$ is high enough. As a result, for any target ratio $\theta^{*}$, there always exists $\bar{s}\left(\theta^{*}\right)<q$ such that the target is reached, which means that the discriminant $\Delta$ in equation (23) must be positive ${ }^{9}$.

Consider first the lowest threshold $c_{l}$. Compared to the no-price impact case, it is now costlier to make use of the asset sale channel due to the existence of a price impact. As long as this price impact is positive, the term $-\frac{q}{\Phi}$ in the denominator of equation (24) is negative so that $c_{l}>c_{u}$. As expected, when $\frac{1}{\Phi}=0$, the critical spreads coincide. As in the no price impact case, the following properties are true.

$$
\frac{\partial c_{l}\left(\alpha, \theta^{*}, \gamma\right)}{\partial \alpha}<0 \quad \frac{\partial c_{l}\left(\alpha, \theta^{*}, \gamma\right)}{\partial \theta^{*}}<0 \quad \frac{\partial c_{l}\left(\alpha, \theta^{*}, \gamma\right)}{\partial \gamma}>0
$$

As already discussed, when $\alpha$ (or $\theta^{*}$ ) increases, the critical spread $c_{l}$ decreases and this decreases the likelihood that the bank will issue new shares. On the contrary, when $\gamma$ increases, this increases the critical spread $c_{l}$ since the asset sale solution is now costlier.

Consider now the highest threshold $c_{h}$ and note that this threshold depends upon $\bar{s}\left(\theta^{*}\right)$ given by equation (22). Since $\bar{s}\left(\theta^{*}\right)$ is positive, when there is a positive price impact, it can readily be seen from equation $(25)$ that $c_{h}>c_{l}$ so that

$$
c_{u}<c_{l}<c_{h}
$$

When $\Phi$ tends to infinity, $\bar{s}\left(\theta^{*}\right)$ tends to a finite quantity, equal to the one as given in proposition 3 , that is, the quantity that must be sold to reach the target capital ratio. Since the two thresholds differ by a term equal to $\frac{2}{\Phi} \bar{s}\left(\theta^{*}\right)$, when $\Phi$ tends to infinity, this term tends to zero so that $c_{h}-c_{l}$ tends to zero.

\footnotetext{
${ }^{9}$ It is also easy to see that when $\Phi$ is high enough, the positive part of $\Delta$ will be close to $\alpha P \theta^{*}$ while the negative part will be close to zero so that $\Delta$ is positive.
} 


\section{Empirical applications to two European systemic banks}

In 2017, two European G-SIIs, the German Deutsche Bank and the Italian bank UniCredit, decided to issue new shares via an underwritten rights offering (standby rights). In such a right offer ${ }^{10}$, existing shareholders are given the right but not the obligation during the subscription period (typically a couple of weeks) to buy the new shares on a prorata basis and at a pre-specified price (the subscription price) which is below the current market price. Moreover, the set of underwriter(s) have committed (in general under some conditions) to acquire all the new shares that would remain unsubscribed. Since these capital increase decisions have been taken in 2016, for the sake of interest, we shall apply the predictions of our model as if we were on December, 31, 2016 and we consider the following question: can we rationally explain the decision of Deutsche Bank and UniCredit to issue new stocks in the first quarter of 2017 ?

\subsection{The case of Deusche Bank}

We shall explain in detail the methodology followed to calibrate the various parameters for the case of Deusche Bank. All the information regarding the capital increase 2017 can be found on the website of Deutsche Bank (https://www.db.com/ir/en/capital-increase-2017.htm). Since the methodology is similar for UniCredit, we will be more brief.

\subsubsection{Empirical analysis}

Basic facts. In the beginning of April 2017, Deutsche Bank successfuly issued 687.5 million new shares stocks for a total value of $€ 8$ billion. In a Media Release as of March 5, 2017, Deutsche Bank announced a target Common Equity Tier 1 ratio, i.e., CET 1 divided by the risk-weighted assets (RWA), equal to 14.1\%. The subscription period of the rights offer was from March 21, 2017 to April, 6, 2017, and the subscription price was $€ 11.65$ per new share (with no par value) while the market price was around $€ 15$ during this period, that is, the discount was approximately equal to 25\%. Moreover, each new share carried the same dividend rights as all other outstanding shares of Deutsche Bank. The capital increase has been underwritten by thirty banks but Credit Suisse, Barclays, Goldman Sachs, BNP Paribas, Commerzbank, HSBC, Morgan Stanley and UniCredit are the main underwriters as each of them committed to subscribe from $6.09 \%$ to $8.28 \%$ of the new shares underwritten. The number of shares increased from 1.3793 billion to 2.066 billion and Deutsche Bank reports (in the media release as of April 7, 2017) that 98.9\% of the subscription rights were exercised. According to Deutsche Bank (see the media release as of April 7, 2017).

Had the capital increase been completed on 31 December 2016, Deutsche Bank's Common Equity Tier 1 (CET1) ratio on that date would have been $14.1 \%$ on a pro forma CRD4 fully loaded basis rather than $11.8 \%$.

\footnotetext{
${ }^{10}$ See for instance the comprehensive review of [Eckbo et al., 2007], see also [Holderness and Pontiff, 2016] for a recent overview of rights offerings in USA.
} 
It is explicitly stated in the prospectus (see p. 113) that existing shareholders that exercise their subscription rights will continue to see their percentage share in the share capital of the Company nearly unchanged. However, for those who decided not to exercise their rights, their percentage ownership in the company's share and their voting rights will be diluted by $33 \%$.

Estimation of the parameters. We need to estimate all the parameters of the model, that is, $v$, $q P, \frac{q}{\Phi}, \alpha, c, \gamma$ and $\theta^{*}$.

From the interim report as of June 2017 (page 32), it is reported that the gross proceeds amount to $€ 8$ billion while the net proceeds amount to $€ 7.9$ billion. As a result, since the cost of issuance is equal to the difference between the gross proceeds and the net proceeds, i.e., it is equal to $€ 0.1$ billion $^{11}$, so that

$$
c=\frac{0.1}{8} \approx 1.25 \%
$$

From the annual report as of December 2016 (see the balance sheet), the total value of the assets, $A$, is equal to $€ 1591$ billion while the value of the cash, $v$, is equal to $€ 181$ billion. As a result, the value of the risky asset $q P=A-v$ is equal to $€ 1410$ billion. From the liabilities side, since total equity is equal to $€ 64.81$ billion, it thus follows that $D=1591-64.81=€ 1526.2$ billion. The balance sheet of Deutsche Bank at the end of December 2016 with only the two items of interest is provided below.

\section{Deutsche Bank's Balance sheet as of December 2016 (in billion)}

\begin{tabular}{|c|c|}
\hline Assets & Liabilities and Equity \\
\hline Cash: $v=181$ & Debt: $D=1526.2$ \\
Risky asset: $q P=1410$ & Equity $: E=64.81$ \\
\hline$A=1591$ & $E+D=1591$ \\
\hline
\end{tabular}

Since the risk-weighted assets (fully loaded) are equal to $€ 357.5$ billion, it thus follows from equation (3) that

$$
\alpha=\frac{357.5}{1410} \approx 25.3 \%
$$

To apply proposition 4, we need an estimation $\frac{q}{\Phi}$. In [Greenwood et al., 2015], see also the related paper of [Duarte and Eisenbach, 2015] they make the assumption that $\frac{1}{\Phi}$ is of the order of $10^{-13}$. Given equation (10), this means that selling for 10 billion (i.e., $s=10^{10}$ ) of the risky asset leads to a price change of 10 bps (i.e., $\frac{s}{\Phi}=10^{-3}=0.1 \%$ ). In this paper, since proposition 4 explicitly depends on $\frac{q}{\Phi}$, we shall proxy this quantity $\frac{q}{\Phi}$ by the total exposure of Deutsche Bank denoted $V_{D B}$ divided by the sum of total exposure denoted $V_{S u m}$, that is $\frac{V_{D B}}{V_{S u m}}$. The ratio $\frac{V_{D B}}{V_{\text {Sum }}}$ is used by supervisors to compute the score of banks considered as G-SIBs (such as Deutsche Bank) for the size indicator. The greater the ratio $\frac{V_{D B}}{V_{S u m}}$, everything else equal, the higher the loss absorbency requirements (capital surcharge) for the bank. The total exposure of Deutsche Bank $V_{D B}$ is available in the annual report but can also be found on the website of the European Banking Authority (EBA)

\footnotetext{
${ }^{11}$ In the prospectus, it is explicitly stated that the maximal amount that Deutsche Bank will pay is $€ 141$ million. Due to the success of the right offer, this amount has been less than $€ 141$ million.
} 
while the sum of the total exposure $V_{\text {Sum }}$ can be found on the website of the Bank for International Settlements (BIS). As of December 2016, $V_{\text {Sum }}=€ 75900$ billion while $V_{D B}=€ 1363$ billion. It thus follows that

$$
\frac{q}{\Phi}=\frac{q P}{\Phi P} \approx \frac{V_{D B}}{V_{\text {Sum }}}=\frac{1363}{75900}=1.8 \%
$$

This approach is obviously disputable but we have not found a natural way to estimate more precisely the price impact of a bank at an aggregate level. Interestingly, the proxy used for $\frac{1}{\Phi}$ is equal to $7.5910^{-13}$, and thus is consistent with the choice of [Greenwood et al., 2015].

The parameter $\gamma$ is by definition equal to $\frac{\mathbb{E} \Pi(q)}{q P}$ and is more delicate to estimate as it depends upon the expected future profits. In 2015 and in 2016, (in part) due to litigation costs, Deutsche Bank made a loss equal respectively to $€ 6.7$ billion and to $€ 1.35$ billion. If we estimate statistically $\gamma$ using years 2015 and 2016 only, $\gamma$ will be negative and this might not correctly reflect the future expected profits. Moreover, since the capital increase has been successful, i.e., $98.9 \%$ of the rights were exercised, the new shares have been bought (by existing shareholders) in the expectation of positive future profit. We thus discard the years 2015 and 2016 and we estimate $\gamma$ using the average of the years 2012, 2013 and 2014, that is, we consider the net income attributable to shareholders divided by the value of the risky assets (i.e., total assets minus cash). The three values found are equal to $0.013 \%, 0.04 \%, 0.098 \%$ respectively so that

$$
\gamma \approx 0.05 \%
$$

Note that if one estimates this parameter $\gamma$ by using years 2009 to 2016, i.e., including the two years where the bank makes losses, the prediction of our model remains unchanged.

From the annual report as of December 2016, p. 257, Common Equity Tier 1 (fully loaded) is equal to $€ 42.28$ billion, Additional Tier 1 is equal to $€ 4.7$ billion and Tier 2 is equal to $€ 12.67$ billion. The total capital fully loaded is equal to $€ 59.6$ billion and is thus lower than the $€ 64.81$ billion reported in the balance sheet because of few regulatory deductions. It thus follows that the Common Equity Tier 1 ratio is equal to $\frac{42.28}{357.5} \approx 11.8 \%$ and the total capital ratio is equal to $\frac{59.6}{357.5} \approx 16.6 \%$. If one adds the $€ 8$ billion of new shares to Common equity Tier 1 , we obtain a Common Equity Tier 1 ratio equal to 14.1\%, as predicted by Deutsche Bank in the media release as of April 7, 2017. Since the target $\theta^{*}$ is expressed in our model as Tier 1 plus Tier 2 divided by the risk-weighted assets, we now have to compute $\theta^{*}$ from the target CET 1 (fully loaded) announced by Deutsche Bank. From the target ratio CET 1 (fully loaded) equal to $14.1 \%$, the target capital ratio $\theta^{*}$ thus is equal to

$$
\theta^{*}=14.1 \%+\left(\frac{4.7+12.67}{357.5}\right) \approx 18.9 \%
$$

To sum-up, the value of the parameters are given below.

$$
c=1.25 \%, \alpha=25.3 \%, \gamma=0.05 \%, \frac{q}{\Phi}=1.8 \%, \quad \theta^{*}=18.9 \%
$$

Before computing the critical spread, let us check whether or not the condition given by equation (16) is satisfied. Since $v+q P-D=59.6, q P=1410$, it thus follows that $\frac{59.6}{1410} \approx 4.2 \%>\frac{q}{\Phi}=1.8 \%$ so that the condition is satisfied. 
Computation of the critical spreads. We are now in a position to compute the critical spread $c_{l}$ provided by the rhs of equation (24) in proposition 4 . By inserting the numerical values found in equation (33), we find a critical spread $c_{l}$ equal to

$$
c_{l}=\frac{0.05 \%}{0.05 \%+25.3 \% \times 18.9 \%-1.8 \%(1-25.3 \% \times 18.9 \%)} \approx 1.6 \%
$$

Since $c=1.25 \%$, it thus follows that $c<c_{l}$ so that our model correctly predicts the decision of Deutsche Bank to issue new shares only. Note interestingly that without price impact, the critical spread is equal to $1.03 \%$ and it is thus optimal to (only) sell assets. For Deutsche bank, the price impact thus seems an important factor to consider in the decision.

In proposition 4 , we provide the two critical spreads $c_{l}$ and $c_{h}$. While only $c_{l}$ is useful for the empirical analysis, it is yet interesting to compute $c_{h}$. To do so, note that the value of the risky asset of Deutsche Bank is equal to $V_{D B}=q P$. Since only $V_{D B}$ is observed in the annual report, we make the assumption that $P=1$, which means that $\bar{s}\left(\theta^{*}\right)$ has to be lower than $q$. In appendix (see sub-section 7.3 in the appendix), we find that $\bar{s}\left(\theta^{*}\right) \approx 269$. The critical spread is equal to

$$
c_{h} \approx 19,5 \%
$$

and is much higher than the critical spread for which the bank issues equity only.

\subsubsection{Robustness check}

A balance sheet with liquid and illiquid assets There are many types of robustness check that can be performed. As in [Admati et al., 2018], we shall here consider the case of asset heterogeneity, that is, some assets are liquid (i.e., marketable assets) and can be sold while others are not (i.e., typically loans) and can not be sold. With two risky assets, a liquid and an illiquid one, the balance sheet of Deutsche bank is now as follows.

\section{Deutsche Bank's Balance sheet as of December 2016 (in billion)}

\begin{tabular}{|c|c|}
\hline Assets & Liabilities and Equity \\
\hline Cash: $v=181$ & Debt: $D=1526.2$ \\
Liquid assets: $q P=1001$ & Equity : $E=64.81$ \\
Illiquid assets : 409 & \\
\hline$A=1591$ & $E+D=1591$ \\
\hline
\end{tabular}

The illiquid assets, subject to credit risk, are loans accounted at fair value but it is important to note that this fair value is not equal to their resale value. As is well-known, due to the adverse selection problem, loans are difficult to resell in the short term even with a discount. The liquid assets, mainly subject to market risk and counterparty risk, include the financial assets through profit or loss ( $€ 743.8$ billion), the financial assets available for sale (€56.22 billion) and various heterogeneous assets. In such a type of risky assets framework, to imply the weight of each risky asset, one must consider the RWA related to the risk of the asset and not the (total) RWA. 
The RWA for each risk is disclosed in the annual report of each bank. The RWA for credit risk is equal to $€ 220.3$ billion, the RWA for counterparty risk is equal to $€ 9.5$ billion, the RWA for market risk for $€ 33.8$ billion and the RWA for operational risk for $€ 92.6$ billion. Of course, it remains unclear whether the operational risk should be related to the banking book (illiquid assets) or to the trading book (liquid assets). To imply the weight $\alpha$ of the liquid asset, we shall thus consider the two polar cases. One in which this operational risk is $100 \%$ related to the banking book and the other one in which it is $100 \%$ related to the trading book. As a result, we obtain a lower and an upper bound for $\alpha$.

- Assume that operational risk is $100 \%$ related to the banking book. As a result, for the numerator, we only consider the RWA for market risk and counterparty risk. The minimum value of $\alpha$ thus is equal to $\underline{\alpha}=\frac{33.8+9.5}{1001}=4.3 \%$.

- Assume now that operational risk is $100 \%$ related to the trading book. As a result, we now add the RWA for operational risk. The maximum value of $\alpha$ thus is equal to $\bar{\alpha}=\frac{33.8+9.5+92.6}{1001}=$ $13.5 \%$.

One can thus conclude that $\alpha \in[4.3 \%, 13.5 \%]$ so that it is always lower than $25.3 \%$. From equation (26), we know that when $\alpha$ decreases, everything else equal, this increases the likelihood that the bank will issue new shares. As a result, abstracting the illiquid asset, it is still optimal to issue new shares and not to sell the liquid assets. Assuming now that the operational risk is $100 \%$ related to the trading book, the (implied) weight of the illiquid asset is equal to $\underline{\nu}=\frac{220.3}{409} \approx 54 \%$, which means that it might be optimal to sell these illiquid assets rather than to issue new shares. However, if one assumes that the resale value of the loans is small enough, it won't be optimal to resell them. In such a case, the optimal liquidation strategy is equivalent to the one postulated in [Cifuentes et al., 2005]; the bank should first sell the liquid assets, and, if needed, the illiquid asset. For the case of Deutsche Bank, if it had to sell assets, liquidating a fraction of the liquid asset would be enough to reach the target. As a result, the illiquid asset plays no role, and we are back to the one risky asset model.

\subsubsection{What happened since 2017?}

We now provide a quick overview of the evolution of the situation of Deutsche Bank since 2017, the last stock issuance. We summarize the annual reports' data from 2015 to 2019 in Table 1 and we provide the stock price evolution since the last four years in Fig. 2. Overall, the CET1 ratio and the leverage ratio have always been satisfied and this observation is consistent with our results (see Proposition 1). From Table 1, one can see an important increase of the CET1 ratio between 2016 and 2017 (explained by the issuance of new stocks) and an increase of the leverage ratio over the years (from $3,5 \%$ in 2015 to $4,2 \%$ in 2019). We can also notice an important asset shrinking over the years since the total assets of the bank decreased from $1629 € b n$ in 2015 to $1298 € b n$ in 2019. This seems to be a trend that can be explained by Deutsche Bank's strategy to increase over time its capital ratios. It is also interesting to point out that on May 11, 2020, Deutsche Bank 


\begin{tabular}{|l||l|l|l|l|}
\hline Year & CET1 ratio & Leverage ratio & $\begin{array}{l}\text { Total assets (in } € \\
\text { bn) }\end{array}$ & $\begin{array}{l}\text { Net income (loss) } \\
\text { (in } € \text { m.) }\end{array}$ \\
\hline 2019 & $13,6 \%$ & $4,2 \%$ & 1298 & $(5265)$ \\
2018 & $13,6 \%$ & $4,1 \%$ & 1348 & 341 \\
2017 & $14 \%$ & $3,8 \%$ & 1475 & $(735)$ \\
2016 & $11,8 \%$ & $3,5 \%$ & 1591 & $(1356)$ \\
2015 & $11,1 \%$ & $3,5 \%$ & 1629 & $(6772)$ \\
\hline
\end{tabular}

Table 1: Deutsche Bank - CET1 ratio, Leverage ratio, Total assets and Net income

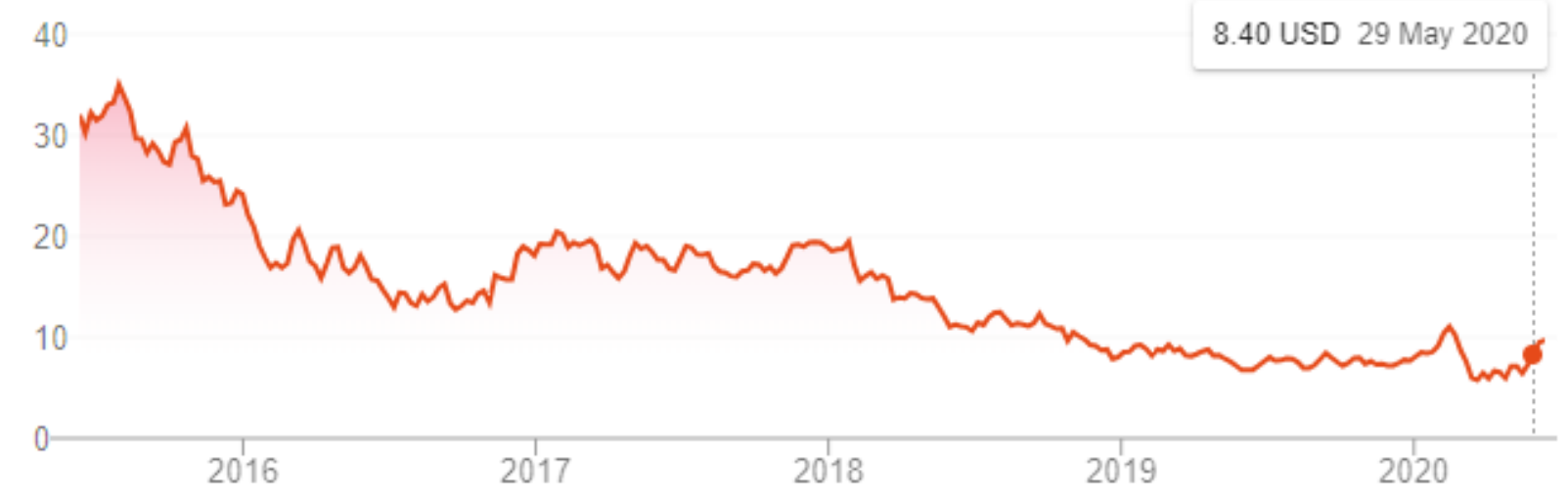

Figure 2: Deutsche Bank stock price evolution

launched an euro-denominated Tier 2 issuance (and announced a public tender offer for senior nonpreferred-debt with a target acceptance volume of 2.0 billion euros) in order to increase its total capital ratio. From Fig. 2, one can clearly see that the stock price is decreasing over time since 2018, which means that the performance of DB is perceived negatively by the market, something which can largely been explained by the fact that since 2015, the bank has been profitable only in 2018.

\subsection{The case of UniCredit}

The analysis of UniCredit is similar to the one of Deutsche Bank so that we do not repeat the way we calibrate the parameters.

\subsubsection{Empirical analysis}

On March 2, 2017, UniCredit ${ }^{12}$ completed its capital increase for an overall amount of $€ 13$ billion and it is stated in a media release that their aim is bring their fully loaded CET 1 capital ratio

\footnotetext{
${ }^{12}$ All the information regarding the capital increase 2017 can be found on the web site of UniCredit, see https://www.unicreditgroup.eu/en/governance/capital-strengthening.html
} 
above $12.9 \%$ at the end of December 2019. The subscription period of the rights issue was (in Italy) from February 6, 2017 to February 23, 2017 and the subscription price was equal to $€ 8.09$ while the market price was around $€ 12.5$ during this period. From the public (interim) report as of June 2017 p. 32, the cost of the capital increase is equal to $€ 0.33$ billion, the difference between the gross proceeds, equal to $€ 13$ billion and the net proceeds equal to $€ 12.67$ billion $^{13}$, so that $c=\frac{0.33}{13}=2.53 \%$. From page 42 of the annual report as of December 2016, the risk-weighted assets is equal to $€ 387.15$ billion, CET 1 is equal to $€ 31.53$ billion, Tier 1 is equal to $€ 35$ billion and the total capital, that includes Tier 2, is equal to $€ 45.15$ billion. The CET 1 capital ratio thus is equal to $8.15 \%$ while the total capital ratio is equal to $11.66 \%$. Since the total value of the assets as of 2016 is equal to $€ 859.5$ billion while the cash is equal to $€ 13.5$ billion, the balance sheet is as follows.

\section{UniCredit's Balance sheet (December 2016)}

\begin{tabular}{|c|c|}
\hline Assets & Liabilities and Equity \\
\hline Cash: $v=13.5$ & Debt: $D=814.35$ \\
Risky asset: $q P=846$ & Equity : $E=45.15$ \\
\hline$A=859.5$ & $E+D=859.5$ \\
\hline
\end{tabular}

The implied weight is equal to $\alpha=\frac{387.15}{846}=45.7 \%$ and note that it is almost two times the one of Deutsche Bank. Using years 2014 and 2015 yields $\gamma \approx 0.21 \%$. From the website of the EBA, the total exposure is equal to $€ 974.4$ billion, so that $\frac{q}{\Phi} \approx \frac{974.4}{75900}=1.3 \%$. If one adds $€ 13$ billion to CET1, the CET 1 capital ratio is equal to $11.5 \%$ (and remains lower than the target of $12.9 \%$, the target in 2019), then the risk-based capital ratio is equal to $15 \%$, i.e., $\theta^{*}=15 \%$. By inserting the numerical values found in equation (33), we find a critical spread $c_{l}$ equal to

$$
c_{l}=\frac{0.21 \%}{0.21 \%+(45.7 \% \times 15 \%)-1.28 \%(1-(45.7 \% \times 15 \%))} \approx 3.57 \%
$$

Since $c=2.53 \%$, it thus follows that $c<c_{l}$ so that our model correctly predicts the decision of Uni Credit to issue new shares only ${ }^{14}$.

As we did for Deutsche Bank, we also provide the critical spread $c_{h}$ and find (see sub-section 7.3 in the appendix) that $c_{h} \approx 14,07 \%$. As for the case of Deutsche Bank $c_{h}$ is much higher than $c_{l}$.

\footnotetext{
${ }^{13}$ In a securities note as of February, 2017, the total amount of expenses have been estimated up to about $€ 500$ million, "including consulting expenses, out-of pocket expenses and underwriting fees calculated at the highest level". The real cost thus has been lower, equal to $€ 330$ million.

${ }^{14}$ It should be noted that in December 2016, UniCredit signed binding agreement for the sale of Pioneer Investments to Amundi (for a price equal to 3.545 billion) in order to increase its fully loaded CET1 ratio of 78 basis points. If we make the assumption that the decision to increase the capital of UniCredit and the decision to sell Pioneer to Amundi have been taken simultaneously, then, our model wrongly predicts the decisions of UniCredit. Note finally that, as for the case of Deutsche Bank, there was no dilution for existing shareholders who decided to "fully subscribe the Offering to the extent to which they are entitled", see the document called the securities note as of February, 2017 (
} 


\begin{tabular}{|l||l|l|l|l|}
\hline Year & CET1 ratio & Leverage ratio & $\begin{array}{l}\text { Total assets (in } € \\
\text { bn) }\end{array}$ & $\begin{array}{l}\text { Net income (loss) } \\
\text { (in € m.) }\end{array}$ \\
\hline 2019 & $13,2 \%$ & $5,5 \%$ & 856 & 3373 \\
2018 & $12,1 \%$ & $5,1 \%$ & 832 & 3892 \\
2017 & $13,7 \%$ & $5,7 \%$ & 837 & 5473 \\
2016 & $8,2 \%$ & $3,6 \%$ & 860 & $(11790)$ \\
2015 & $10,6 \%$ & $4,6 \%$ & 860 & 1694 \\
\hline
\end{tabular}

Table 2: Unicredit - CET1 ratio, Leverage ratio, Total assets and Net income

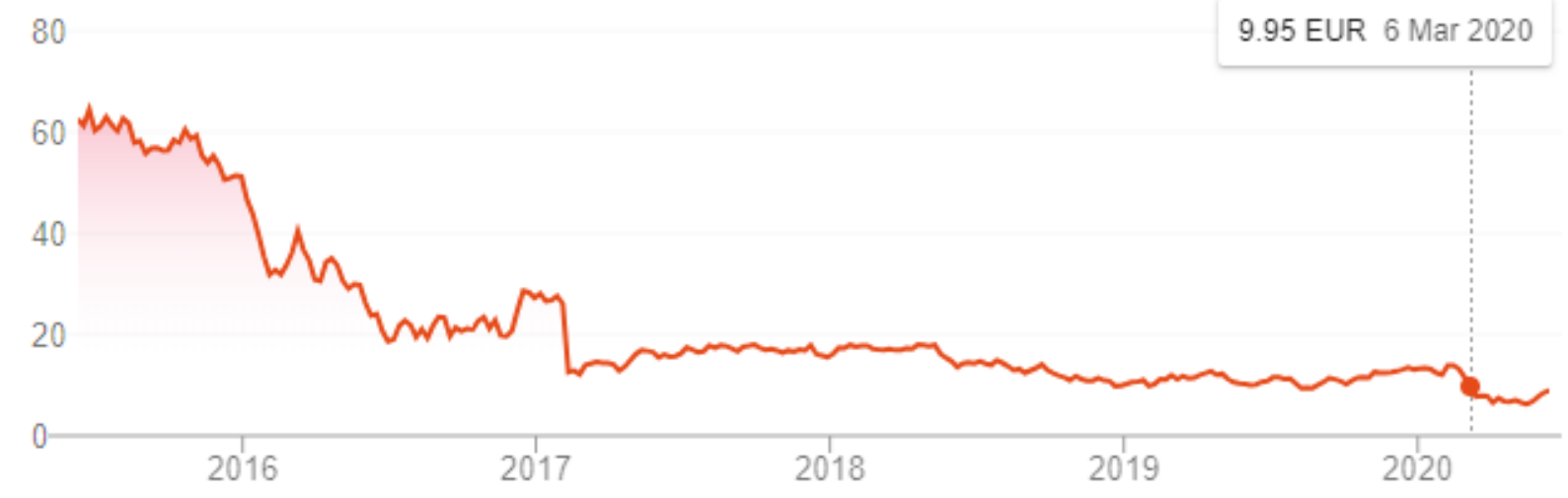

Figure 3: Unicredit stock price evolution

\subsubsection{What happened since 2017?}

We summarize the annual reports' data of Unicredit from 2015 to 2019 in Table 2 and we report in Figure 3 the stock price evolution. The CET1 ratio and the leverage ratio have always been satisfied for Unicredit and it is interesting to point out that the leverage ratio have increased over time, from 4,6\% in 2015 to $5,5 \%$ in 2019 (far higher than the regulatory requirement as well). Regarding the stock price, after a significant drop between 2015 and the beginning of 2017, it has remained fairly stable.

\section{The spread as a $U$-shaped function of the gross proceeds: an exploratory analysis}

Up to now, we made the assumption that the spread is equal to $\frac{K}{I}+c$, where $c$ is a constant, which means that the spread is a decreasing function of the gross proceeds $I$. However, in their paper, [Altınkılıç and Hansen, 2000] argue that, from the underwriting theories, the issuer's spread should be a $U$-shaped function. It should first decrease with $I$ because of a fixed cost effect (i.e., because $\frac{K}{I}$ is decreasing with $I$ ) and should then increase due to a rising placement cost effect (i.e., finding more buyers becomes more difficult and thus riskier for the underlying set of underwriters). They 


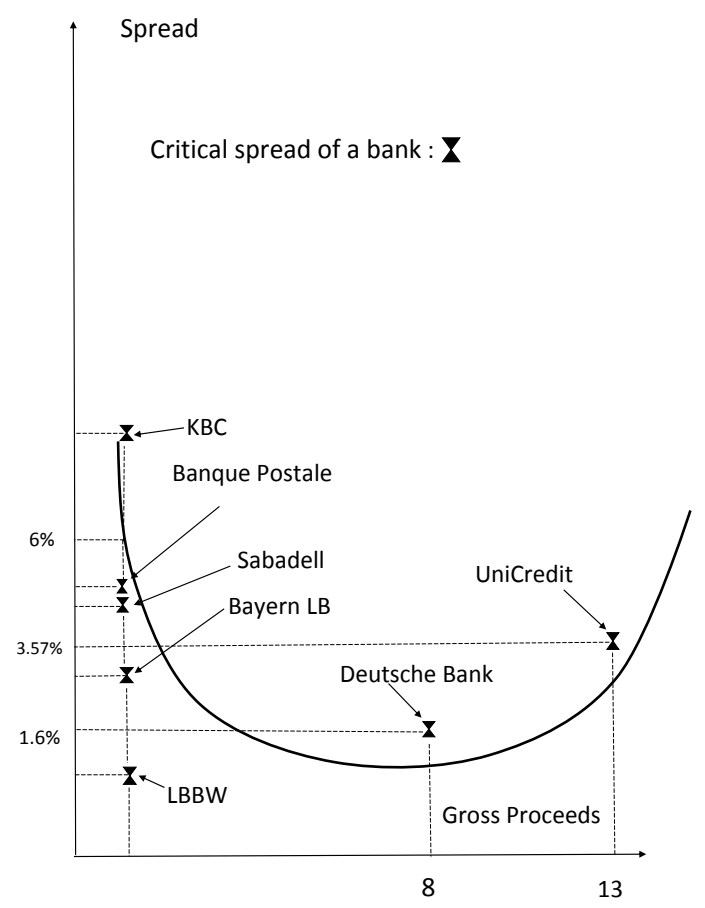

Figure 4: Spread as a U-shaped function and critical spread

find empirical results that are consistent with a family of $U$-shaped functions (spectrum theory). More recently, in [De Jonghe and Öztekin, 2015], the authors find empirically that, to reach a target capital ratio, smaller banks tend to sell assets while large banks tend to issue new stocks. They note that this is a good news for financial stability as smaller banks have by definition a total value of their assets (much) lower than systemic banks and are less interconnected. We shall now suggest that if one assumes that the spread function is a $U$-shaped function of the gross proceeds, then, our model might provide a theoretical explanation to the empirical findings of [De Jonghe and Öztekin, 2015].

From the 2017-list of 35 banks reported on the website of the $\mathrm{EBA}^{15}, 12$ are considered as G-SIIs. By definition, a bank which is listed on the 2017-list has an overall exposure measure of more than $€ 200$ billion. When one inspects the 23 banks that are not considered as G-SIIs, some of them have a total value of their assets between $€ 200$ billion and $€ 250$ billion. Compared with many G-SIIs for which the total value of the assets typically exceeds $€ 1500$ billion, for these smaller banks, a capital increase in million (i.e., less than one billion) might be enough to increase (significantly) their CET1 capital ratio. For instance, on June, 2016, Erste Group Bank decided to issue additional Tier 1 capital, more precisely non-cumulative bonds with an annual coupon rate equal to $8.875 \%$ and with a total nominal value of $€ 500$ billion. They also disclose in their annual report as of 2016 that their minimum target capital ratio is a CET1 capital ratio fully loaded at least equal to $12.75 \%$ for 2019 and they observe that the target has been reached since the CET1 capital ratio fully loaded is equal

\footnotetext{
${ }^{15} \mathrm{http}: / /$ www.eba.europa.eu/risk-analysis-and-data/global-systemically-important-institutions/2017
} 
to $12.8 \%$ in 2016 . To be able to derive the critical spread of these smaller European banks, i.e., to predict the optimal decision of those non-systemic banks, we shall make the assumptions that

$$
I\left(\theta^{*}\right)=500 \text { million (euros) }
$$

that is, we assume that given the target capital ratio which is not observed in general, the gross proceeds are equal $€ 500$ million. For these banks with a total value of the assets typically lower than $€ 250$ billion, the price impact is very low, i.e., close to $\frac{250}{75900} \approx 0.33 \%$ as of 2016 . To facilitate the exercise, we consider as negligible this price impact and we assume that $\frac{1}{\Phi}=0$. In such a situation, as we have already seen, the optimization problem reduces to a linear programming problem for which it is never optimal to mix the channels of adjustment. We shall focus on banks that belong to countries of the Euro zone and that have total assets lower than $€ 250$ billion. Since Erste Group Bank reaches its target capital ratio in 2016, we have decided not to include this bank in our exercise. Overall, five banks are considered, Bayern LB (German), Banque Postale (French), Sabadell (Spanish), LBBW (German), and KBC (Belgium). The (unique) critical spread of each bank is given below (details related to the computation can be found in the appendix)

$$
c_{u \text { Bayern }}=3.38 \% \quad c_{u B \text { Post }}=5.6 \% \quad c_{u \text { Sabadell }}=5.4 \% \quad c_{u L B B W}=1.23 \% \quad c_{u K B C}=11.48 \%
$$

In our (small) sample of banks, the average spread is equal to $5.5 \%$, which is a result consistent with the finding of [Boyson et al., 2016] since found a spread (for issuing common stocks) equal to $5.02 \%$. Let

$$
\operatorname{Spread}(I)=\frac{K}{I}+c(I)
$$

be the spread as a function of $I$, where $c(I)$ is the non constant marginal cost (of issuance) function. Assume now, as in Fig. 4, that the spread is a $U$-shaped function of $I$. We already know that for Deutsche Bank and UniCredit, it was optimal to issue new shares only because the observed spread was higher than their critical spread, something that we reproduce on Fig. 4. If one now assumes that the spread that must be paid by the bank is equal to $6 \%$ for gross proceeds of $€ 0.5$ billion, i.e., $c(0.5)=6 \%$, then, except for the Belgium bank BKC, it is optimal to sell assets only for the other banks. We do not claim that this approach in terms of $U$-shaped function constitutes the definitive answer to the empirical finding of [De Jonghe and Öztekin, 2015] but it provides a simple and credible explanation since the price impact should not be an issue for small banks.

\section{Conclusion}

We presented in this paper a simple model of optimal choice of channel(s) of adjustment when the aim of the bank is to reach a target capital ratio. We considered the case of two European systemic banks, Deutsche Bank and UniCredit, for which the optimal target is explicitly disclosed and we have shown that our model is able to predict the observed decision of these two banks to issue new shares only. We then considered a model in which the spread is $U$-shaped, and this simple approach 
might explain the empirical finding of [De Jonghe and Öztekin, 2015] in which large banks tend to issue new shares while small banks tend to sell assets.

Under Basel III, the minimum capital requirement will continue to increase so that large banks will have to increase their capital ratio in order to reach their target. The approach undertaken in this paper can be of interest for regulators and supervisors to forecast those banks that will most likely reach their target capital ratios by selling an important portion of their risky assets. 


\section{$7 \quad$ Mathematical appendix}

\subsection{Preliminary results}

From equation (13) when $I=0$, the risk-based capital ratio is equal to

$$
\theta(s, 0):=\frac{E(s, 0)}{\operatorname{RWA}(s)}=\frac{v-D+q P\left(1-\frac{s}{\Phi}\right)}{\alpha(q-s) P\left(1-\frac{s}{\Phi}\right)}
$$

which is a non-linear function of the quantity sold $s \in[0, q]$. We want to study the evolution of $\theta(s, 0)$ as a function of $s$ assuming that $\Phi \in(2 q, \infty)$. Throughout this appendix, $E^{\prime}(s, 0), \operatorname{RWA}^{\prime}(s)$ and $\theta_{s}^{\prime}(s, 0)$ will respectively denote the partial derivative of that function with respect to $s$. By definition of the derivative:

$$
\theta_{s}^{\prime}(s, 0)=\frac{E^{\prime}(s, 0) \operatorname{RWA}(s)-E(s, 0) \operatorname{RWA}^{\prime}(s)}{(\operatorname{RWA}(s))^{2}}
$$

The sign of $\theta_{s}^{\prime}(s, 0)$, denoted $\operatorname{Sgn}\left(\theta_{s}^{\prime}(s, 0)\right)$, thus is the sign of the numerator of equation (40)

$$
\operatorname{Sgn}\left(\theta_{s}^{\prime}(s, 0)\right)=\operatorname{Sgn}\left[E^{\prime}(s, 0) \operatorname{RWA}(s)-E(s, 0) \operatorname{RWA}^{\prime}(s)\right]
$$

From equation (39), it is not difficult to show that

$$
\operatorname{Sgn}\left(\theta_{s}^{\prime}(s, 0)\right)=\operatorname{Sgn}\left(-\frac{q P}{\Phi} \alpha(q-s) P\left(1-\frac{s}{\Phi}\right)+\alpha P\left[1-\left(\frac{2 s-q}{\Phi}\right)\right]\left[v-D+q P\left(1-\frac{s}{\Phi}\right)\right]\right)
$$

Note importantly that $\theta_{s}^{\prime}(s, 0)$ is a quadratic equation in $s$ so that $\theta_{s}^{\prime}(s, 0)$ needs not be a monotonic function of $s \in[0, q]$.

Lemma A 1 If $\Phi>\underline{\Phi}$ (or equivalently if $E(q, 0)>0)$, then, $\theta_{s}^{\prime}(0,0)>0$

Proof. Letting $s=0$ in equation (42) leads to $\operatorname{Sgn}\left(\theta_{s}^{\prime}(0,0)\right)=v-D+q P+(v-D) \frac{q}{\Phi}$. Since $v-D+q P>0$, if $(v-D)>0$, then, it follows immediately that $\theta_{s}^{\prime}(0,0)>0$. However, in general, $(v-D)<0$. Since $E(q, 0)=v-D+q P\left(1-\frac{q}{\Phi}\right)>0$ by assumption, it is easy to show that $v-D+q P+(v-D) \frac{q}{\Phi}>v-D+q P\left(1-\frac{q}{\Phi}\right)$ is equivalent to $\frac{q}{\Phi}(v-D+q P)>0$ so that $\theta_{s}^{\prime}(0,0)>0 \square$

Lemma A 2 There exists a smallest $\bar{\Phi}>0$ such that for all $\Phi>\bar{\Phi}$ and all $s \in(0, q), \theta_{s}^{\prime}(s, 0)>0$.

Proof. From equation (42), when $\Phi$ tends to infinity, for all $s \in(0, q)$, the rhs of equation (42) tends to $\alpha P(v+q P-D)>0$. Since the rhs of equation (42) is a continuous function of $\Phi$, there thus exists a smallest market depth denoted $\bar{\Phi}$ such that for all $\Phi>\bar{\Phi}$ and all $s \in(0, q), \theta_{s}^{\prime}(s, 0)>0$

Remark. It is actually not difficult to show that a necessary but not sufficient condition for $\theta_{s}^{\prime}(s, 0)>0$ is $E(s, 0)>0$.

We now provide an upper bound for $\bar{\Phi}$. 
Lemma A $3 \bar{\Phi} \leq q\left(1+\frac{q P}{E(0, q)}\right)$

Proof. From equation (42) to the sign of $\theta_{s}^{\prime}(s, 0)$ is equal to

$$
\underbrace{\left(-\frac{q P}{\Phi} \alpha(q-s) P\left(1-\frac{s}{\Phi}\right)\right)}_{A(s)}+\underbrace{\alpha P\left[1-\left(\frac{2 s-q}{\Phi}\right)\right]\left[v-D+q P\left(1-\frac{s}{\Phi}\right)\right]}_{B(s)}
$$

We want to find a sufficient condition such that equation (43) is positive for all $s$ and note that $A(s)<0$ while $B(s)>0$ for each $s$ since $E(0, q)=v-D+q P\left(1-\frac{q}{\Phi}\right)>0$. Note also that $B(s)>\alpha P\left[1-\left(\frac{2 s-q}{\Phi}\right)\right] E(0, q)$ for each $s$. In the same vein, $A(s)<-\frac{q P}{\Phi} \alpha q P\left(1-\frac{s}{\Phi}\right)$ for each $s$. Simplifying by $\alpha P$, this leads to $\left[1-\left(\frac{2 s-q}{\Phi}\right)\right] E(0, q)>\frac{q P}{\Phi} q\left(1-\frac{s}{\Phi}\right)$ which in turn is always true if $\left[1-\frac{q}{\Phi}\right] E(0, q)>\frac{q^{2} P}{\Phi}$ and is in turn equivalent to $\Phi>q\left(1+\frac{q P}{E(0, q)}\right)$. We thus have shown that for each $s, \alpha P\left[1-\left(\frac{2 s-q}{\Phi}\right)\right] E(0, q)>\frac{q P}{\Phi} \alpha q P\left(1-\frac{s}{\Phi}\right)$, so that for each $s B(s)>A(s)$. Since we found a sufficient condition for which $\theta_{s}^{\prime}(s, 0)$ for each $s$, it may be the case that $\bar{\Phi}<q\left(1+\frac{q P}{E(0, q)}\right)$

Lemma A 4 If $\Phi \in(\underline{\Phi}, \bar{\Phi})$, then, there exists two roots $\widehat{s}_{1}$ and $\widehat{s}_{2}$ (with $\widehat{s}_{1}<\widehat{s}_{2}$ ) such that $\theta_{s}^{\prime}\left(\widehat{s}_{i}, 0\right)=$ 0 for $i=1,2$.

Proof. When $\Phi \in(\underline{\Phi}, \bar{\Phi})$, by definition of $\bar{\Phi}$, the risk-based capital ratio $\theta(s, 0)$ cannot be an increasing function of $s$ for each $s \in(0, q)$. From lemma A 1 , we know that when $\Phi>\underline{\Phi}$ (or equivalently when $E(q, 0)>0), \theta_{s}^{\prime}(0,0)>0$. Since $E(q, 0)>0$ and $\lim _{s \rightarrow q} \operatorname{RWA}(s) \rightarrow 0$ so that $\lim _{s \rightarrow q} \theta(s, 0) \rightarrow \infty$, there thus exists two roots $\widehat{s}_{1}$ and $\widehat{s}_{2}$, with $0<\widehat{s}_{1}<\widehat{s}_{2}<q$, such that $\theta_{s}^{\prime}\left(\widehat{s}_{i}, 0\right)=0$ for $i=1,2$ and such that $\theta_{s}^{\prime}(s, 0)>0$ for $s \in\left(0, \widehat{s}_{1}\right), \theta_{s}^{\prime}(s, 0)<0$ for $s \in\left(\widehat{s}_{1}, \widehat{s}_{2}\right)$ and $\theta_{s}^{\prime}(s, 0)>0$ for $s \in\left(\widehat{s}_{2}, q\right) \square$ Figure 5 illustrates the lemma.

\subsection{Proofs}

Proof of proposition 1. The leverage ratio is defined as $L=\frac{E}{q P}$. Since $\theta=\frac{E}{\alpha q P}$, it thus follows that $\theta=\frac{L}{\alpha}$. Since $\theta=\theta_{\min }$ by assumption, it thus follows that $\alpha=\frac{L}{\theta_{\min }}$. Under the optimal solution, we know that $\theta\left(s^{*}, I^{*}\right)=\theta^{*}$. Noting that for each $(s, I) \in[0, q) \times \mathbb{R}^{+}, \theta(s, I)=\frac{L(s, I)}{\alpha}$, it thus follows that $\theta\left(s^{*}, I^{*}\right)=\frac{L\left(s^{*}, I^{*}\right)}{\alpha}$. Using now the fact that $\alpha=\frac{L}{\theta_{\min }}, \theta\left(s^{*}, I^{*}\right)=\frac{L\left(s^{*}, I^{*}\right)}{\alpha}$ is equivalent to $L\left(s^{*}, I^{*}\right)=L \frac{\theta^{*}}{\theta_{\min }}$ since $\theta\left(s^{*}, I^{*}\right)=\theta^{*}$. Recalling that $\frac{\theta^{*}}{\theta_{\min }}>1$, it thus follows that $L\left(s^{*}, I^{*}\right)>L \geq L_{\min }$

Proof of proposition 2. When $c<1$ and $s=0$, the risk-based capital ratio $\theta(0, I)$ is an increasing function of $I$. As a result, for each $\theta^{*} \in \mathbb{R}^{+}$, there exists a unique $\bar{I}\left(\theta^{*}\right)$ such that $\theta\left(0, \bar{I}\left(\theta^{*}\right)\right)=\theta^{*}$ and this concludes the first part of the proof. For the second part of the proof, note first that $\lim _{s \rightarrow q} \operatorname{RWA}(s) \rightarrow 0$. Since $\Phi>\underline{\Phi} \Longleftrightarrow E(q, 0)>0$, it thus follows that $\lim _{s \rightarrow q} \theta(s, 0):=\frac{E(s, 0)}{\operatorname{RWA}(s)} \rightarrow$ $\infty$. Since $\Phi>\bar{\Phi}, \theta(s, 0)=\frac{E(s, 0)}{\operatorname{RWA}(s)}$ is a continuous function of $s \in[0, q)$ and for each $\theta^{*} \in \mathbb{R}^{+}$, there exists a unique $\bar{s}\left(\theta^{*}\right)<q$ such that $\theta\left(\bar{s}\left(\theta^{*}\right), 0\right)=\theta^{*}$ 


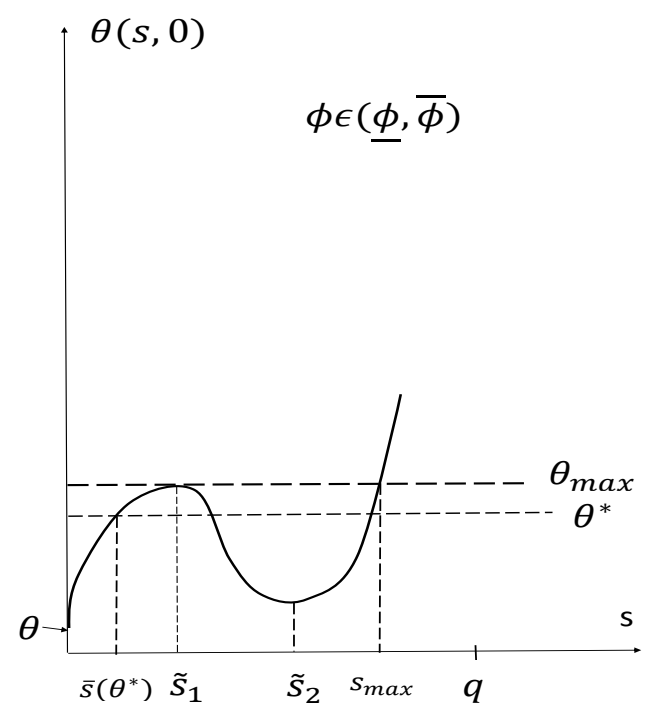

Figure 5: The risk-based capital is not an increasing function of $s$

We have defined $\bar{s}\left(\theta^{*}\right)$ such that $\theta\left(\bar{s}\left(\theta^{*}\right), 0\right)=\theta^{*}$. Let us now define the function $I\left(s, \theta^{*}\right) \in$ $\left[0, \bar{I}\left(\theta^{*}\right)\right]$ such that $\theta\left(s, I\left(s, \theta^{*}\right)\right)=\theta^{*}$ for each $s \in\left[0, \bar{s}\left(\theta^{*}\right)\right]$. Let $C(s, I)=s P\left(\gamma+\frac{s}{\Phi}\right)+c I=k$, where $k>0$ be a level curve of the cost function and let $I(s, k)$ be such that $C(s, I(s, k))=k$ for each $s$.

Proposition A 1 The function $I\left(s, \theta^{*}\right)$ is a decreasing and strictly convex function of $s$ while the function $I(s, k)$ is a decreasing and strictly concave function of $s$.

The proof will consist in few simple results.

Claim A 1 Assume that $I_{2}>I_{1}$. Then, for all $s \in[0, q), \theta\left(s, I_{2}\right)>\theta\left(s, I_{1}\right)$.

Proof. Since by definition $\theta(s, I)=\frac{v-D+q P\left(1-\frac{s}{\Phi}\right)+(1-c) I}{\alpha(q-s) P\left(1-\frac{s}{\Phi}\right)}$, it is elementary to show that if $I_{2}>I_{1}$, then, for all $\Phi>\underline{\Phi}$ (but this is true for all $\Phi>0$ ) and all $s \in[0, q), \theta\left(s, I_{2}\right)>\theta\left(s, I_{1}\right)$.

From equation (13), it is easy to show that the iso-target curve $I\left(s, \theta^{*}\right)$ is equal to

$$
I\left(s, \theta^{*}\right):=I(s)=\frac{\left.\theta^{*} \alpha(q-s) P\left(1-\frac{s}{\Phi}\right)-\left[v-D+q P\left(1-\frac{s}{\Phi}\right)\right]\right]}{1-c}
$$

and note that from claim A 1 , if $I\left(s, \theta^{*}\right)>0$, then $s<\bar{s}\left(\theta^{*}\right)$.

Claim A 2 For each $s \in\left(0, \bar{s}\left(\theta^{*}\right)\right), \theta_{s}^{\prime}(s, 0)>0$ is equivalent to $I^{\prime}\left(s, \theta^{*}\right)<0$

Proof. Along the iso target curve, i.e., as long as $s$ is such that $\theta\left(s, I\left(s, \theta^{*}\right)\right)=\theta^{*}, d \theta(s, I)=0$, which is equivalent to $d \theta(s, I)=\frac{\partial \theta(s, I)}{\partial s} d s+\frac{\partial \theta(s, I)}{\partial I} d I=0$ and finally yields $\frac{d I}{d s}:=I^{\prime}(s)=-\frac{\frac{\partial \theta(s, I)}{\partial s}}{\frac{\partial \theta(s, I)}{\partial I}}$ 
where $\frac{\partial \theta(s, I)}{\partial I}>0$. Since $\frac{\partial \theta(s, I)}{\partial I}>0$, for each $s \in(0, q), I^{\prime}(s)<0$ is equivalent to $\frac{\partial \theta(s, I)}{\partial s}>0$ for any $I \geq 0$

It is easy to show that $C(s, I(s, k))=k$ is equivalent to

$$
I(s, k)=\frac{k}{c}-\left(\frac{s P\left(\gamma+\frac{s}{\Phi}\right)}{c}\right)
$$

We are now in a position to complete the proof. From claim A 2, we already know that $I^{\prime}(s)<0$ and it is easy to see that $I^{\prime \prime}(s)=\left(\frac{1}{c}\right) \frac{\alpha \theta^{*} 2 P}{\Phi}>0$ for each $s \in\left(0, \bar{s}\left(\theta^{*}\right)\right)$, which shows that $I(s)$ is a decreasing and strictly convex function of $s$. From equation (45), it is easy to show that $I^{\prime}(s, k)=-\frac{1}{c}\left(\gamma P+\frac{2 s P}{\Phi}\right)<0$ while $I^{\prime \prime}(s, k)=-\left(\frac{1}{c}\right) \frac{2 P}{\Phi}<0$. As a result, the function $I(s, k)$ is a decreasing and strictly concave function of $s$ for any $k>0$

Proof of proposition 3. Since the optimization program is a linear programming problem, the solution is either $(0, \bar{I})$ or $(\bar{s}, 0)$ and note that $\theta<\theta^{*}$ is equivalent to $-v+D+q P\left(\theta^{*} \alpha-1\right)>0$. Consider the pure equity solution. It is easy to show that $\bar{I}=\frac{q P\left(\alpha \theta^{*}-1\right)-(v-D)}{1-c}>0$ so that $C(0, \bar{I})=\frac{c}{1-c}\left(q P\left(\alpha \theta^{*}-1\right)-(v-D)\right)>0$. Consider now the pure asset sale solution. It is easy to show that $\bar{s}=\frac{\left.q P\left(\alpha \theta^{*}-1\right)-(v-D)\right)}{\alpha P \theta^{*}}>0$ so that $C(\bar{s}, 0)=\frac{\gamma\left[q P\left(\alpha \theta^{*}-1\right)-(v-D)\right]}{\alpha \theta^{*}}>0$. Let $c_{u}$ be the critical spread for which $C(\bar{s}, 0)=C(0, \bar{I})$. Since $C(\bar{s}, 0)=C(0, \bar{I}) \Longleftrightarrow \frac{c_{u}}{1-c_{u}}=\frac{\gamma}{\alpha \theta^{*}}$, this yields the desired critical spread $c_{u}=\frac{\gamma}{\gamma+\alpha \theta^{*}}$. It is easy to show that $c<c_{u}$ is equivalent to $C(\bar{s}, 0)>C(0, \bar{I})$ so that it is optimal to issue new equity only, i.e., $\left(s^{*}, I^{*}\right)=(0, \bar{I})$. Solving $\theta\left(0, I^{*}\right)=\theta^{*}$ yields $I^{*}=\frac{\alpha q P \theta^{*}-E}{1-c}$. When $c>c_{u}$, it is optimal to only sell assets. Solving $\theta\left(s^{*}, 0\right)=\theta^{*}$ yields $s^{*}=q-\frac{E}{\alpha P \theta^{*}}$

Proof of proposition 4. Instead of solving the optimization problem using Kuhn and Tucker, we make use of the specific problem under consideration and we use the fact that we have only two variables $s$ and $I$. By inserting equation (44) into the cost function $C(s, I)$, we thus obtain a cost function $C\left(s, I\left(s, \theta^{*}\right)\right) \equiv C(s)$ that only depends on $s$. The optimization problem thus reduces to a uni-dimensional minimization problem. Since $C^{\prime \prime}(s)>0$ for each $s \in(0, q)$, i.e., the cost function is convex in $s$, it thus follows that $s^{*}$ such that $C^{\prime}\left(s^{*}\right)=0$ is a global minimum. Computations of $C^{\prime}\left(s^{*}\right)=0$ is equivalent to

$$
s^{*}=\frac{\frac{\alpha \theta^{*} c}{1-c}\left(1+\frac{q}{\Phi}\right)-\left(\gamma+\frac{c q}{(1-c) \Phi}\right)}{\frac{2}{\Phi}\left(1+\frac{\alpha \theta^{*} c}{1-c}\right)}=\frac{\left(\alpha \theta^{*}\left(1+\frac{q}{\Phi}\right)+\gamma-\frac{q}{\Phi}\right) c-\gamma}{\frac{2}{\Phi}\left(\alpha \theta^{*}-1\right) c+\frac{2}{\Phi}}
$$

We notice that and it suffices now to solve $s^{*}\left(c_{l}\right)=0$, i.e., to solve $\frac{\alpha \theta^{*} c_{l}}{1-c_{l}}\left(1+\frac{q}{\Phi}\right)-\left(\gamma+\frac{c_{l} q}{\left(1-c_{l}\right) \Phi}\right)=0$ to obtain the desired critical spread $c_{l}$. When $c<c_{l}$, since $s^{*}$ is non-negative, $s^{*}=0$ and it is thus optimal to only issue new equity, $I^{*}=\bar{I}\left(\theta^{*}\right)=\frac{\alpha q P \theta^{*}-E}{1-c}$ this concludes the first part of the proof.

Consider now the highest critical spread $c_{h}$. We first note that $s^{*}(c)$ is a strictly increasing function and

$$
I(s)=\frac{1}{1-c}\left(\theta^{*} \alpha(q-s) P\left(1-\frac{s}{\Phi}\right)-E+\frac{q P s}{\Phi}\right)
$$


is a strictly decreasing function of $s$ between 0 and $q$. So $I\left(s^{*}(c)\right)$ is a strictly decreasing function of $c$.

To prove the existence and uniqueness of $c_{h}$, assume that $c=1$. In such a case, $\frac{\partial \theta(s, I)}{\partial I}=0$ while $\frac{\partial C(s, I)}{\partial I}>0$ for each $\in[0, q)$ and each $I \geq 0$ so that $I^{*}=0$ when $c=1$. Therefore there exists a critical spread $c_{h} \in(0,1)$ such that $I\left(s^{*}\left(c_{h}\right)\right)=0$ and for all $c>c_{h}$ we have $s^{*}=\bar{s}\left(\theta^{*}\right)$ and $I^{*}=0$. We find the expression of $\bar{s}\left(\theta^{*}\right)$ by solving $I\left(\bar{s}\left(\theta^{*}\right)\right)=0$ (it is the smaller root of the polynomial $I(s))$ :

$$
I(s)=0 \Longleftrightarrow \alpha P \frac{\theta^{*}}{\Phi} s^{2}+\left(\frac{q P}{\Phi}-\alpha P \theta^{*}\left(1+\frac{q}{\Phi}\right)\right) s+\left(D-v-q P+\alpha P \theta^{*} q\right)=0
$$

The discriminant $\Delta$ is equal to:

$$
\Delta=\left(\alpha P \theta^{*}\left(1+\frac{q}{\Phi}\right)-\frac{q P}{\Phi}\right)^{2}-4 \frac{\left(\alpha P \theta^{*}\right)^{2} q}{\Phi}\left(1-\frac{\theta}{\theta^{*}}\right)
$$

And the left root $\bar{s}\left(\theta^{*}\right)$ is equal to:

$$
\bar{s}\left(\theta^{*}\right)=\frac{\alpha P \theta^{*}\left(1+\frac{q}{\Phi}\right)-\frac{q P}{\Phi}-\sqrt{\Delta}}{\frac{2 \alpha P \theta^{*}}{\Phi}}
$$

To find the expression of $c_{h}$, we solve: $s^{*}\left(c_{h}\right)=\bar{s}\left(\theta^{*}\right) \Longleftrightarrow\left(\alpha \theta^{*}\left(1+\frac{q}{\Phi}\right)+\gamma-\frac{q}{\Phi}\right) c_{h}-\gamma=$ $\bar{s}\left(\theta^{*}\right) \frac{2}{\Phi}\left(\alpha \theta^{*}-1\right) c_{h}+\frac{2}{\Phi}$.

Which gives:

$$
c_{h}=\frac{\gamma+\frac{2}{\Phi} \bar{s}\left(\theta^{*}\right)}{\gamma+\alpha \theta^{*}-\frac{q}{\Phi}\left(1-\alpha \theta^{*}\right)+\frac{2}{\Phi} \bar{s}\left(\theta^{*}\right)\left(1-\alpha \theta^{*}\right)}
$$

\subsection{Computation of the critical threshold $c_{h}$}

\subsubsection{The case of Deutsche Bank}

First, we compute $\Delta$ :

$$
\begin{aligned}
& \Delta=(25,3 \% \times 18,9 \% \times(1+1,8 \%)-1,8 \%)^{2}-4 \times(25,3 \% \times 18,9 \%)^{2} \times 1,8 \% \times\left(1-\frac{16,6 \%}{18,9 \%}\right) \\
& \approx 9,21 \times 10^{-4}
\end{aligned}
$$

Then, we can compute $\bar{s}\left(\theta^{*}\right)$ :

$$
\bar{s}\left(\theta^{*}\right)=\frac{25,3 \% \times 18,9 \% \times(1+1,8 \%)-1,8 \%-\sqrt{9,21 \times 10^{-4}}}{2 \times 25,3 \% \times 18,9 \% \times \frac{1,8 \%}{1410}} \approx 269
$$


And finally we can compute $c_{h}$ :

$$
c_{h}=\frac{0.05 \%+2 \times \frac{1,8 \%}{1410} \times 269}{0.05 \%+25.3 \% \times 18.9 \%-1.8 \%(1-25.3 \% \times 18.9 \%)+2 \times \frac{1,8 \%}{1410} \times 269 \times(1-25,3 \% \times 18,9 \%)} \approx 19,5 \%
$$

\subsubsection{The case of Unicredit}

First, we compute $\Delta$ :

$$
\Delta=(45,7 \% \times 15 \% \times(1+1,3 \%)-1,3 \%)^{2}-4 \times(45,7 \% \times 15 \%)^{2} \times 1,3 \% \times\left(1-\frac{11,66 \%}{15 \%}\right)
$$

$\approx 3,131 \times 10^{-3}$

Then, we can compute $\bar{s}\left(\theta^{*}\right)$ :

$$
\bar{s}\left(\theta^{*}\right)=\frac{45,7 \% \times 15 \% \times(1+1,3 \%)-1,3 \%-\sqrt{3,131 \times 10^{-3}}}{2 \times 45,7 \% \times 15 \% \times \frac{1,3 \%}{846}} \approx 230
$$

And finally we can compute $c_{h}$ :

$$
c_{h}=\frac{0.21 \%+2 \times \frac{1,3 \%}{846} \times 230}{0.21 \%+45,7 \% \times 15 \%-1.8 \%(1-45,7 \% \times 15 \%)+2 \times \frac{1,3 \%}{846} \times 230 \times(1-45,7 \% \times 15 \%)} \approx 14,07 \%
$$




\subsection{Critical spread for European banks with total assets between $€ 200$ billion and $€ 300$ billion}

Bayern LB (Germany). As of December 2016, the RWA is equal to $€ 65.20$ billion, CET1 is equal to $€ 9.54$ billion while the total capital is equal to $€ 11.05$ billion. The total capital ratio thus is equal to $17 \%$. The total value of the assets is equal to $€ 212.15$ billion and the value of cash is equal to $€ 2.1$ billion so that $q P=210.05$. From these data, $\alpha=31 \%$. Since CET1 is equal to $14.7 \%$, when the bank raises $€ 0.5$ billion, the CET1 capital ratio moves to $15.45 \%$, i.e., it increases by 75 bps. As a result, the total capital ratio, which becomes the target, is now is equal to $\theta^{*}=17.7 \%$. By estimating $\gamma$ using the years 2015, 2016, we find respectively a value equal to $0.20 \%$ and $0.184 \%$ so that the average is equal to $\gamma=0.192 \%$. It thus follows from equation (17) that

$$
c_{u \text { Bayern }}=3.38 \% \text {. }
$$

Banque Postale (France). As of December 2016, the RWA is equal to $€ 59.53$ billion, CET1 is equal to $€ 8.17$ billion while the total capital is equal to $€ 11.55$ billion. The total capital ratio thus is equal to $19.4 \%$. The total value of the assets is equal to $€ 229.6$ billion and the value of cash is equal to $€ 2.7$ billion so that $q P=226.9$. From these data, $\alpha=26.2 \%$. Since CET1 is equal to $13.7 \%$, when the bank raises $€ 0.5$ billion, the CET1 capital ratio moves to $14.5 \%$, i.e., it increases by almost 80 bps. As a result, the total capital ratio, which becomes the target, is now is equal to $\theta^{*}=20.24 \%$. By estimating $\gamma$ using the years 2015, 2016, we find respectively a value equal to $0.325 \%$ and $0.3 \%$ so that the average is equal to $\gamma=0.3125 \%$. It thus follows from equation (17) that

$$
c_{u B P}=5.6 \%
$$

SABADELL (Spain). As of December ${ }^{16} 2016$, the RWA is equal to $€ 86.07$ billion, CET1 is equal to $€ 10.33$ billion while the total capital is equal to $€ 11.851$ billion. The total capital ratio thus is equal to \%. The total value of the assets is equal to $€ 212.5$ billion and the value of cash is equal to $€ 11.68$ billion so that $q P=200.82$. From these data, $\alpha=42.8 \%$. Since CET1 is equal to $12 \%$, when the bank raises $€ 0.5$ billion, the CET1 capital ratio moves to $12.6 \%$, i.e., it increases by 60 bps. As a result, the total capital ratio, which becomes the target, is now is equal to $\theta^{*}=14.35 \%$. By estimating $\gamma$ using the years 2015, 2016, we find respectively a value equal to $0.351 \%$ and $0.353 \%$ so that the average is equal to $\gamma=0.352 \%$. It thus follows from equation (17) that

$$
c_{u \text { Sabadell }}=5.4 \% \text {. }
$$

LBBW (Germany). As of December 2016, the RWA is equal to $€ 77.4$ billion, CET1 (fully loaded) is equal to $€ 11.76$ billion while the total capital is equal to $€ 16.64$ billion. The total capital ratio thus is equal to $21.5 \%$. The total value of the assets is equal to $€ 243.6$ billion and the value of cash is equal to $€ 13.53$ billion so that $q P=230.07$. From these data, $\alpha=33.6 \%$. Since CET1 is equal to $15.2 \%$, when the bank raises $€ 0.5$ billion, the CET1 capital ratio moves to $15.83 \%$, i.e., it

\footnotetext{
${ }^{16}$ They placed 500 billion of Tier 2 capital in 2016.
} 
increases by $63 \mathrm{bps}$. As a result, the total capital ratio, which becomes the target, is now is equal to $\theta^{*}=22.15 \%$. By estimating $\gamma$ using the years 2015,2016 , we find respectively a value equal to $0.18 \%$ and $0.0043 \%$ so that the average ${ }^{17}$ is equal to $\gamma=0.093 \%$. It thus follows from equation (17) that

$$
c_{u L B B W}=1.23 \%
$$

KBC (Belgium). As of December 2016, the RWA is equal to $€ 78.48$ billion, CET1 is equal to $€ 12.65$ billion while the total capital is equal to $16.24 €$ billion. The total capital ratio thus is equal to $20.7 \%$. The total value of the assets is equal to $€ 239.33$ billion and the value of cash is equal to $€ 20.14$ billion so that $q P=219.2$. From these data, $\alpha=35.8 \%$. Since CET1 is equal to $14.3 \%$, when the bank raises $€ 0.5$ billion, the CET1 capital ratio moves to $14.95 \%$, i.e., it increases by 43 bps. As a result, the total capital ratio, which becomes the target, is now is equal to $\theta^{*}=21.33 \%$. By estimating $\gamma$ using the years 2015, 2016, we find respectively a value equal to $1.06 \%$ and $0.924 \%$ so that the average is equal to $\gamma=0.99 \%$. It thus follows from equation (17) that

$$
c_{u K B C}=11.48 \%
$$

\section{References}

[Admati et al., 2018] Admati, A. R., DeMarzo, P. M., Hellwig, M. F., and Pfleiderer, P. (2018). The leverage ratchet effect. The Journal of Finance, 73(1):145-198.

[Altınkılıç and Hansen, 2000] Altınkılıç, O. and Hansen, R. S. (2000). Are there economies of scale in underwriting fees? evidence of rising external financing costs. The Review of Financial Studies, 13(1):191-218.

[Bakkar et al., 2019] Bakkar, Y., De Jonghe, O., and Tarazi, A. (2019). Does banks' systemic importance affect their capital structure and balance sheet adjustment processes? Journal of Banking \& Finance, page 105518.

[BCBS, 2015] BCBS (2015). Making supervisory stress tests more macroprudential: Considering liquidity and solvency interactions and systemic risk.

[Berger et al., 2008] Berger, A. N., DeYoung, R., Flannery, M. J., Lee, D., and Öztekin, Ö. (2008). How do large banking organizations manage their capital ratios? Journal of Financial Services Research, 34(2-3):123-149.

[BoE, 2017] BoE (2017). The financial policy committee's review of the leverage ratio.

[Bostandzic et al., 2018] Bostandzic, D., Irresberger, F., Juelsrud, R., and Weiss, G. N. (2018). Bank capital requirements and systemic risk: Evidence from a quasi-natural experiment. Leeds University Business School Working Paper, (18-02).

\footnotetext{
${ }^{17}$ The net consolidated profit is equal to 0.142 billion in 2016 while it was equal to 0.531 billion in 2015 . This explains why the value of $\gamma$ is very low for the year 2016.
} 
[Boyson et al., 2016] Boyson, N. M., Fahlenbrach, R., and Stulz, R. M. (2016). Why don't all banks practice regulatory arbitrage? evidence from usage of trust-preferred securities. The Review of Financial Studies, 29(7):1821-1859.

[Braouezec, 2010] Braouezec, Y. (2010). Modigliani-miller theorem. Encyclopedia of Quantitative Finance.

[Braouezec and Wagalath, 2018] Braouezec, Y. and Wagalath, L. (2018). Risk-based capital requirements and optimal liquidation in a stress scenario. Review of Finance, 22(2):747-782.

[Braouezec and Wagalath, 2019] Braouezec, Y. and Wagalath, L. (2019). Strategic fire-sales and price-mediated contagion in the banking system. European Journal of Operational Research, $274(3): 1180-1197$.

[Brunnermeier, 2009] Brunnermeier, M. K. (2009). Deciphering the liquidity and credit crunch 2007-2008. Journal of Economic perspectives, 23(1):77-100.

[Calomiris and Tsoutsoura, 2010] Calomiris, C. W. and Tsoutsoura, M. (2010). Underwriting costs of seasoned equity offerings: Cross-sectional determinants and technological change, 1980-2008. In Columbia Business School Working paper.

[Cifuentes et al., 2005] Cifuentes, R., Ferrucci, G., and Shin, H. S. (2005). Liquidity risk and contagion. Journal of the European Economic Association, 3:556-566.

[Cohen and Scatigna, 2016] Cohen, B. H. and Scatigna, M. (2016). Banks and capital requirements: channels of adjustment. Journal of Banking $\&$ Finance, 69:S56-S69.

[De Jonghe and Öztekin, 2015] De Jonghe, O. and Öztekin, Ö. (2015). Bank capital management: International evidence. Journal of Financial Intermediation, 24(2):154-177.

[Décamps et al., 2011] Décamps, J.-P., Mariotti, T., Rochet, J.-C., and Villeneuve, S. (2011). Free cash flow, issuance costs, and stock prices. The Journal of Finance, 66(5):1501-1544.

[Diamond and Rajan, 2011] Diamond, D. W. and Rajan, R. G. (2011). Fear of fire sales, illiquidity seeking, and credit freezes. The Quarterly Journal of Economics, 126(2):557-591.

[Duarte and Eisenbach, 2015] Duarte, F. and Eisenbach, T. M. (2015). Fire-sale spillovers and systemic risk. Review of Financial Studies, Revise and Resubmit.

[Eckbo et al., 2007] Eckbo, B. E., Masulis, R. W., and Norli, O. (2007). Security offerings. Handbook of corporate finance: Empirical corporate finance, 1:233-373.

[(ESRB), 2015] (ESRB), E. S. R. B. (2015). The ESRB handbook on operationalising macroprudential policy in the banking sector. Addendum: Macroprudential leverage ratios.

[Flannery and Rangan, 2006] Flannery, M. J. and Rangan, K. P. (2006). Partial adjustment toward target capital structures. Journal of financial economics, 79(3):469-506. 
[French et al., 2010] French, K. R., Baily, M. N., Campbell, J. Y., Cochrane, J. H., Diamond, D. W., Duffie, D., Kashyap, A. K., Mishkin, F. S., Rajan, R. G., Scharfstein, D. S., et al. (2010). The Squam Lake report: fixing the financial system. Princeton University Press.

[Gomes, 2001] Gomes, J. F. (2001). Financing investment. American Economic Review, pages $1263-1285$.

[Greenwood et al., 2015] Greenwood, R., Landier, A., and Thesmar, D. (2015). Vulnerable banks. Journal of Financial Economics, 115(3):471-485.

[Gropp et al., 2019] Gropp, R., Mosk, T., Ongena, S., and Wix, C. (2019). Banks response to higher capital requirements: Evidence from a quasi-natural experiment. The Review of Financial Studies, 32(1):266-299.

[Hanson et al., 2011] Hanson, S., Kashyap, A., and Stein, J. (2011). A macroprudential approach to financial regulation. Journal of Economic Perspectives, 25(1):3-28.

[Harris and Raviv, 1991] Harris, M. and Raviv, A. (1991). The theory of capital structure. the Journal of Finance, 46(1):297-355.

[Holderness and Pontiff, 2016] Holderness, C. G. and Pontiff, J. (2016). Shareholder nonparticipation in valuable rights offerings: New findings for an old puzzle. Journal of Financial Economics, $120(2): 252-268$.

[Juelsrud and Wold, 2020] Juelsrud, R. E. and Wold, E. G. (2020). Risk-weighted capital requirements and portfolio rebalancing. Journal of Financial Intermediation, 41:100806.

[Kapan and Minoiu, 2018] Kapan, T. and Minoiu, C. (2018). Balance sheet strength and bank lending: Evidence from the global financial crisis. Journal of Banking 6 Finance, 92:35-50.

[Klinac and Ercegovac, 2018] Klinac, I. and Ercegovac, R. (2018). Banking system adjustment to regulatory capital requirements. Croatian Economic Survey, 20(2):69-96.

[Kok and Schepens, 2013] Kok, C. and Schepens, G. (2013). Bank reactions after capital shortfalls.

[Mayordomo and Rodríguez-Moreno, 2020] Mayordomo, S. and Rodríguez-Moreno, M. (2020). How do european banks cope with macroprudential capital requirements. Finance Research Letters, page 101459 .

[Meckling and Jensen, 1976] Meckling, W. H. and Jensen, M. C. (1976). Theory of the firm: Managerial behavior, agency costs and ownership structure. Journal of financial economics, 3(4):305360.

[Memmel and Raupach, 2010] Memmel, C. and Raupach, P. (2010). How do banks adjust their capital ratios? Journal of Financial Intermediation, 19(4):509-528. 
[Myers, 2001] Myers, S. C. (2001). Capital structure. Journal of Economic perspectives, 15(2):81102.

[Öztekin and Flannery, 2012] Öztekin, Ö. and Flannery, M. J. (2012). Institutional determinants of capital structure adjustment speeds. Journal of financial economics, 103(1):88-112.

[Shimizu, 2015] Shimizu, K. (2015). Adjusting denominators of capital ratios: Evidence from japanese banks. Journal of Financial Stability, 19:60-68.

[Shleifer and Vishny, 2011] Shleifer, A. and Vishny, R. (2011). Fire sales in finance and macroeconomics. The Journal of Economic Perspectives, 25(1):29-48.

[Stiglitz, 1988] Stiglitz, J. E. (1988). Why financial structure matters. Journal of Economic Perspectives, 2(4):121-126.

[Tirole, 2010] Tirole, J. (2010). The theory of corporate finance. Princeton University Press. 